\title{
Role of CCR5 in IFN- $\gamma$-induced and cigarette smoke-induced emphysema
}

\author{
Bing Ma,1 Min-Jong Kang,, Chun Geun Lee, ${ }^{1}$ Svetlana Chapoval, ${ }^{1}$ Wei Liu,, ${ }^{1}$ Qingsheng Chen, ${ }^{1}$ \\ Anthony J. Coyle, ${ }^{2}$ José M. Lora, ${ }^{2}$ Dominic Picarella, ${ }^{2}$ Robert J. Homer, ${ }^{3,4}$ and Jack A. Elias ${ }^{1}$
}

\begin{abstract}
${ }^{1}$ Section of Pulmonary and Critical Care Medicine, Yale University School of Medicine, New Haven, Connecticut, USA. ${ }^{2}$ Department of Biology, Inflammation Division, Millennium Pharmaceuticals Inc., Cambridge, Massachusetts, USA. ${ }^{3}$ Department of Pathology, Yale University School of Medicine, New Haven, Connecticut, USA. ${ }^{\text {P}}$ athology and Laboratory Medicine Service, VA-CT Health Care System, West Haven, Connecticut, USA.
\end{abstract}

\begin{abstract}
Th1 inflammation and remodeling characterized by tissue destruction frequently coexist in human diseases. To further understand the mechanisms of these responses, we defined the role(s) of CCR5 in the pathogenesis of IFN- $\gamma$-induced inflammation and remodeling in a murine emphysema model. IFN- $\gamma$ was a potent stimulator of the CCR5 ligands macrophage inflammatory protein-1 $\alpha /$ CCL-3 (MIP-1 $\alpha / C C L-3)$, MIP-1 $\beta / C C L-4$, and RANTES/CCL-5, among others. Antibody neutralization or null mutation of CCR5 decreased IFN- $\gamma$-induced inflammation, DNA injury, apoptosis, and alveolar remodeling. These interventions decreased the expression of select chemokines, including CCR5 ligands and MMP-9, and increased levels of secretory leukocyte protease inhibitor. They also decreased the expression and/or activation of Fas, FasL, TNF, caspase-3, -8, and -9, Bid, and Bax. In accordance with these findings, cigarette smoke induced pulmonary inflammation, DNA injury, apoptosis, and emphysema via an IFN- $\gamma$-dependent pathway(s), and a null mutation of CCR5 decreased these responses. These studies demonstrate that IFN- $\gamma$ is a potent stimulator of CC and CXC chemokines and highlight the importance of CCR5 in the pathogenesis of IFN- $\gamma$-induced and cigarette smoke-induced inflammation, tissue remodeling, and emphysema. They also demonstrate that CCR5 is required for optimal IFN- $\gamma$ stimulation of its own ligands, other chemokines, MMPs, caspases, and cell death regulators and the inhibition of antiproteases.
\end{abstract}

\section{Introduction}

The prototypic Th1/Tc1 cytokine IFN- $\gamma$ plays a key role in the regulation of diverse immune responses, including pathogen recognition, antigen processing and presentation, cellular proliferation, microbicidal effector activation, and leukocyte trafficking (1). In keeping with its important biologic functions, dysregulated IFN- $\gamma$ production has been implicated in a large number of diseases, including atherosclerosis (2), Crohn disease (3), Schistosoma infection (4), coeliac disease (5), rheumatoid arthritis (6), periodontitis (7), Bechet disease (8), aphthous ulcers (9), autoimmune gastritis (10), and uveoretinitis (11). An interesting feature of many of these responses is the close approximation of Th1/Tc1 inflammation and remodeling characterized by tissue atrophy and/or destruction. This can be appreciated in the joint erosions in rheumatoid arthritis, ulcerations in Bechet and aphthous lesions, gingival atrophy in periodontal disease, gastric atrophy in autoimmune gastritis, ocular destruction in uveoretinitis, and histologic necrosis in mycobacterial granulomas (6-12). This is also seen in pulmonary emphysema, where alveolar septal rupture and enhanced type I cytokine production, increased numbers of $\mathrm{CD} 3^{+}$and $\mathrm{CD} 8^{+}$cells that produce IFN- $\gamma$, and increased levels of the IFN- $\gamma$ target gene IP-10/CXCL10 are juxtaposed (13-18). Studies from our labora-

Nonstandard abbreviations used: BAL, bronchoalveolar lavage; COPD, chronic obstructive pulmonary disease; dox, doxycycline; I-TAC, interferon-inducible T cell $\alpha$ chemoattractant; MCP, monocyte chemoattractant protein; Mig, monokine induced by $\gamma$ interferon; MIP- $1 \alpha$, macrophage inflammatory protein-1 $\alpha$; PI, propidium iodide; SDF-1, stromal cell-derived factor-1; SLPI, secretory leukocyte protease inhibitor; TIMP, tissue inhibitor of metalloproteinase.

Conflict of interest: The authors have declared that no conflict of interest exists.

Citation for this article: J. Clin. Invest. 115:3460-3472 (2005).

doi:10.1172/JCI24858. tory have also demonstrated that the transgenic overexpression of IFN- $\gamma$ in the adult murine lung causes pulmonary emphysema (19). Surprisingly, although there is an impressive amount of knowledge regarding the mechanisms of IFN- $\gamma$-induced immunomodulation (reviewed in ref. 1), the mechanisms of IFN- $\gamma$-induced tissue inflammation and remodeling have not been adequately defined.

Chronic obstructive pulmonary disease (COPD) is a generic term that includes emphysema and chronic bronchitis $(20,21)$. For more than 40 years, the protease-antiprotease hypothesis has dominated thinking in this area. This theory proposes that the normal lung is protected by an antiprotease "shield" that negates the effects of proteases in the airway or parenchyma $(20,21)$. It also proposes that emphysema is generated as a result of an increase in proteases and/ or a decrease in antiproteases, with this proteolytic excess causing alveolar septal rupture by digesting septal matrix proteins $(20,21)$. In keeping with recent studies highlighting the Th1/Tc1 inflammation in lungs from patients with $\operatorname{COPD}(13,14,16,18,22,23)$ and our studies demonstrating that IFN- $\gamma$ causes protease-antiprotease abnormalities and emphysema in the murine lung (19), it has been assumed that the Th1/Tc1 inflammatory response is the cause of the protease-antiprotease abnormalities in pulmonary emphysema. However, recent studies have added complexity to this concept of disease pathogenesis by demonstrating that there are also increased levels of structural cell apoptosis in lungs from patients with emphysema and animal models of this disorder (24-28). Surprisingly, the relationships among the inflammatory, protease-antiprotease, and apoptosis alterations in COPD are poorly understood, and the effects of interventions that alter inflammation on other aspects of this remodeling response have not been adequately evaluated.

CCR5 is a $\mathrm{G}$ protein-coupled chemokine receptor that binds macrophage inflammatory protein-1 $\alpha /$ CCL-3 (MIP-1 $\alpha /$ CCL-3, 
A

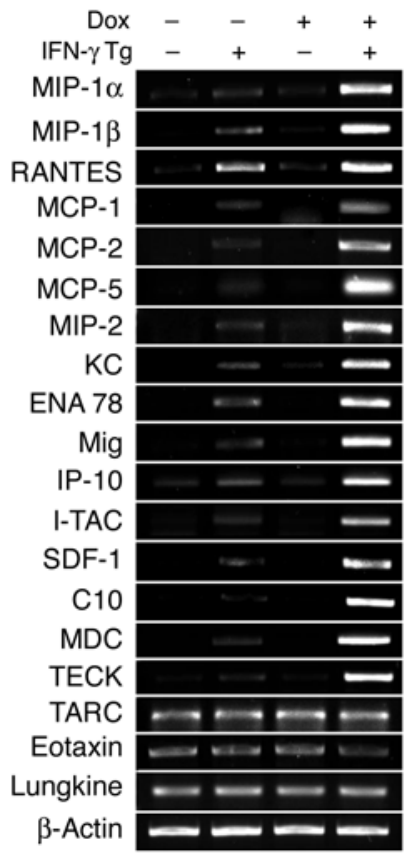

B

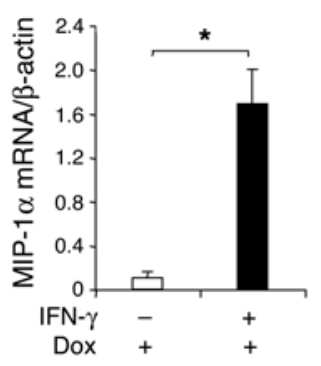

C

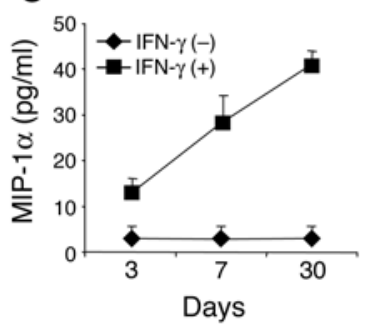

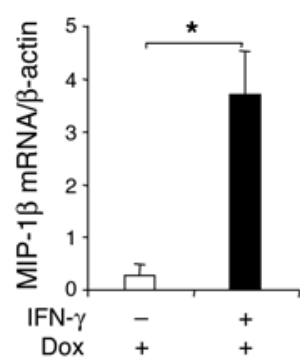
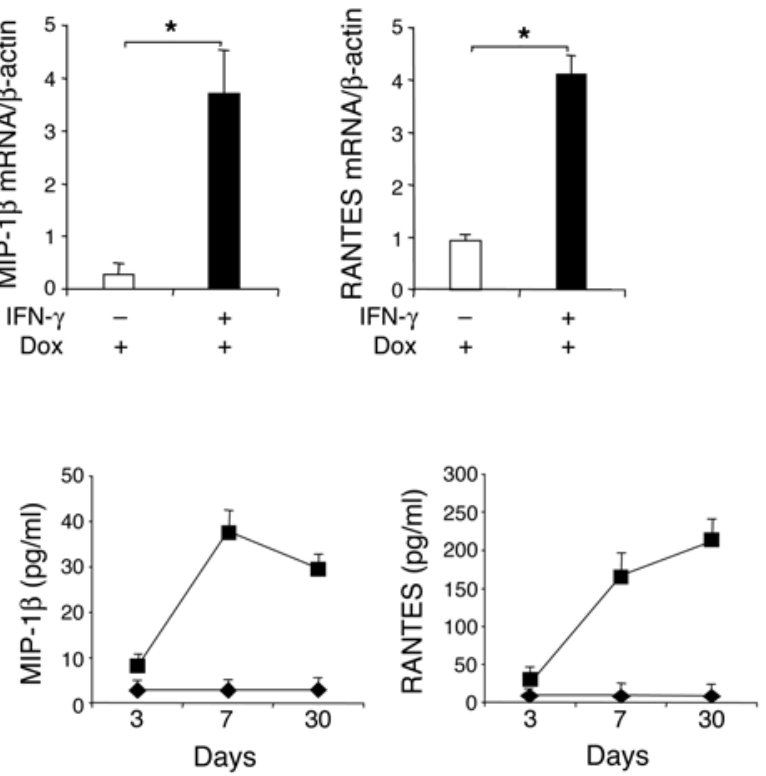

\section{Figure 1}

IFN- $\gamma$ regulation of pulmonary chemokines. $\mathrm{Tg}^{-}$and $\mathrm{Tg}^{+}$mice were given normal or dox water for up to 1 month. The levels of mRNA encoding the noted chemokines in lungs from mice on dox for 1 month were evaluated by RT-PCR (A) and real-time RT-PCR (B), and the levels of BAL chemokine protein were evaluated by ELISA (C). Each evaluation in $\mathbf{A}$ is representative of a minimum of 4 similar experiments. The values in $\mathbf{B}$ and $\mathbf{C}$ represent the mean \pm SEM of evaluations in a minimum of 4 animals. ${ }^{*} P<0.05$ in $\mathbf{B}$. In $\mathbf{C}, P<0.05$ at all time points for MIP-1 $\alpha$ and MIP-1 $\beta$ and at 7 and 30 days for RANTES. MDC, macrophage-derived protein; TECK, thymus-expressed chemokine; TARC, thymus- and activation-regulated chemokine.

MIP-1 $\beta / C C L-4$, and RANTES/CCL-5 and serves as a coreceptor for HIV (29). It is expressed on granulocytes, dendritic cells, macrophages, $\mathrm{CD}^{+}$cells, memory $\mathrm{CD}^{+}$cells, and stromal cells and at high levels on Th1 lymphocytes (29-33). CCR5 plays a critical role in Th1 inflammation and immunity, where it is required for the successful control of a variety of infectious agents, including tuberculosis, cryptococcus, and toxoplasma (29, 31, 34-36) and is expressed in exaggerated quantities in Tc1-dominated responses, including those in tuberculosis, sarcoidosis, Wegner granulomatosis, rheumatoid arthritis, periodontitis, and acute and chronic transplant rejection $(7,31,34,37-41)$. In these responses, CCR5 plays an important role in the pathogenesis of tissue inflammation, protease production, tissue remodeling (41), and local cell death responses $(42,43)$. Despite its frequent coexpression with IFN- $\gamma$ and its important roles in inflammation, protease production, and apoptosis, the roles of CCR5 in the pathogenesis of IFN- $\gamma$-induced inflammation, tissue remodeling, and pulmonary emphysema have not been formally investigated.

We hypothesized that IFN- $\gamma$ is a potent stimulator of pulmonary chemokines and that CCR5-ligand binding plays an important role in the pathogenesis of IFN- $\gamma$-induced inflammation and remodeling in vivo. To test this hypothesis, we characterized the expression of CC and CXC chemokines in transgenic mice in which IFN- $\gamma$ was overexpressed in a lung-specific fashion and defined the effects of CCR5 neutralization or a null mutation of CCR5 on IFN- $\gamma-$ induced inflammation and remodeling in these animals. These studies demonstrate that IFN- $\gamma$ is a potent stimulator of a variety of chemokines, including the CCR5 ligands MIP-1 $\alpha /$ CCL-3,
MIP-1 $\beta / C C L-4$, and RANTES/CCL-5 in the murine lung. They also demonstrate that CCR5 neutralization or a deficiency of CCR5 significantly decreases IFN- $\gamma$-induced inflammation and remodeling and that IFN- $\gamma$ stimulates the production of select chemokines, MMPs, and cell death regulators via CCR5-dependent mechanisms. Last, they provide additional disease relevance by demonstrating that cigarette smoke exposure induces emphysema via IFN- $\gamma$-dependent mechanisms and that this response is ameliorated in CCR5-null mutant mice.

\section{Results}

Effect of IFN- $\gamma$ on CCR5 chemokine ligands. To further define the mechanisms that mediate IFN- $\gamma$-induced tissue alterations, we determined whether IFN- $\gamma$ altered the expression and or production of CC and CXC chemokines that might be expected to contribute to these responses. In lungs from $\mathrm{Tg}^{-}$mice on normal or doxycycline (dox) water, the levels of mRNA encoding MIP-1 $\alpha / C C L-3$, MIP-1 $\beta /$ CCL-4, and RANTES/CCL-5 were at or below the limits of detection of our assays (Figure $1 \mathrm{~A}$ ). In contrast, IFN- $\gamma$ was a potent stimulator of MIP- $1 \alpha / C C L-3$, MIP- $1 \beta / C C L-4$, and RANTES/CCL-5 mRNA and protein in lungs from $\mathrm{Tg}^{+}$mice. The mRNA effects were seen after as few as 3 days of dox administration and persisted throughout the 3-month study interval in RT-PCR evaluations (Figure 1A and data not shown). Similar results were seen with real-time RT-PCR mRNA quantification (Figure 1B). Increases in levels of cytokine protein were also seen after as few as 3-7 days of dox administration and remained significantly elevated after 1 month of dox administration (Figure 1C). These effects were 


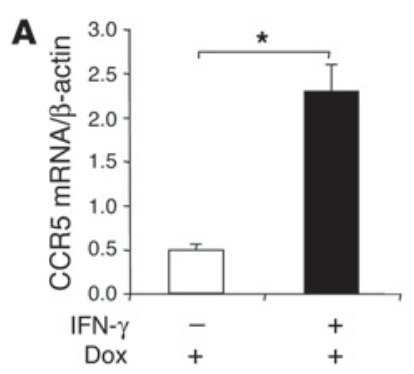

B
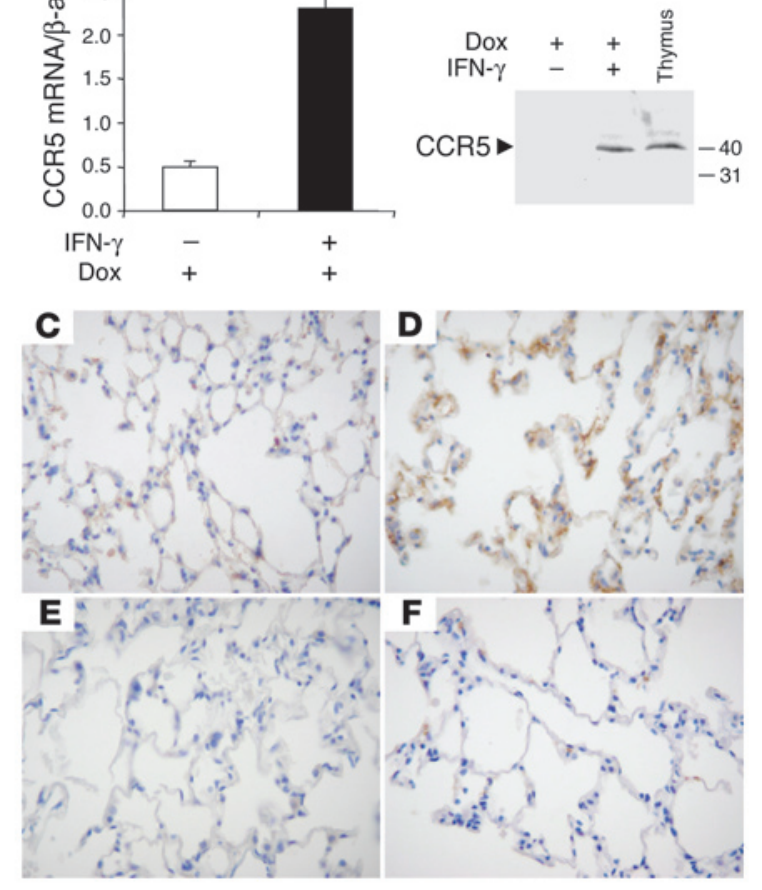

not specific for these cytokine moieties, as prominent induction of monocyte chemoattractant protein-1/CCL-2 (MCP-1/CCL-2), MCP-2/CCL-8, MCP-5/CCL-12, MIP-2/CXCL2/3, KC/CXCL-1, eosinophil neutrophil-activating-78/CXCL-5 (ENA-78/CXCL-5), monokine induced by $\gamma$ interferon/CXCL-9 (Mig/CXCL-9), interferon-inducible protein 10/CXCL-10 (IP-10/CXCL-10), interferoninducible $\mathrm{T}$ cell $\alpha$ chemoattractant/CXCL-11 (I-TAC/CXCL-11), stromal cell-derived factor-1/CXCL-12 (SDF-1/CXCL-12), C10/ CCL-6, macrophage-derived chemokine/CCL-22 (MDC/CCL-22), and thymus-expressed chemokine/CCL25 (TECK/CCL25) were also noted (Figure 1A). In contrast, eotaxin/CCL-11, thymus- and activation-regulated chemokine/CCL-17 (TARC/CCL-17), and lungkine/CXCL-15 were not similarly regulated (Figure 1A). These studies demonstrate that IFN- $\gamma$ is a potent and selective stimulator of pulmonary chemokines.

Effect of IFN- $\gamma$ on CCR5. Because prominent alterations in MIP-1 $\alpha / C C L-3$, MIP-1 $\beta / C C L-4$, and RANTES/CCL-5 were noted, studies were next undertaken to define the effects of IFN- $\gamma$ on their receptor, CCR5. Levels of CCR5 mRNA and protein that were near or below the limits of detection of our assays were noted in lungs from $\mathrm{Tg}^{-}$mice

\section{Figure 3}

Effect of CCR5 neutralization/ablation on IFN- $\gamma$-induced inflammation. (A and $\mathbf{B}$ ) $\mathrm{Tg}^{-}$and $\mathrm{Tg}^{+}$mice were placed on dox water and treated with anti-CCR5 or control Ig for 4 weeks. (C and D) $\mathrm{CCR}^{+/+}$and $\mathrm{CCR}^{-/-} \mathrm{Tg}^{-}$and $\mathrm{Tg}^{+}$mice were treated with dox water for 4 weeks. BAL cell recovery and differential were then evaluated. The values represent the mean \pm SEM of evaluations in a minimum of 4 mice in each group; ${ }^{*}<0.05$. Eo, eosinophil; Neu, neutrophil; Lym, lymphocyte; Mac, macrophage.

\section{Figure 2}

CCR5 in IFN- $\gamma$-transgenic mice. $\mathrm{Tg}^{-}$and $\mathrm{Tg}^{+}$mice were given normal or dox water for 1 month. The levels of CCR5 mRNA and protein in lungs from these mice were evaluated by real-time RT-PCR $(\mathbf{A})$ and Western blot analysis (B), respectively. The CCR5 in the pulmonary specimens is compared with that in a thymus-positive control. (C-F) Immunohistochemistry was used to compare the CCR5 in lungs from $\mathrm{Tg}^{-}$mice stained with anti-CCR5 (C), $\mathrm{Tg}^{+}$mice stained with anti-CCR5 (D), $\mathrm{Tg}^{+}$mice stained with control antibody (E), and $\mathrm{Tg}^{+}$mice with a null mutation of CCR5 stained with anti-CCR5 (F). The values in A represent the mean \pm SEM of evaluations in a minimum of 4 animals. Each evaluation in $\mathbf{B}-\mathbf{F}$ is representative of a minimum of 4 similar experiments. Original magnification, $\times 40 .{ }^{*} P<0.05$.

on normal water or dox water and $\mathrm{Tg}^{+}$mice on normal water (Figure 2, A and B and data not shown). In contrast, the levels of CCR5 mRNA and protein were markedly increased in dox-treated IFN- $\gamma$ transgenic animals (Figure 2, A and B). To localize this protein, immunohistochemistry was also undertaken. These studies demonstrate that CCR5 is in an interstitial location in lungs from $\mathrm{Tg}^{+}$ mice (Figure 2, C-F). This staining was CCR5 specific, as it was not noted in IFN- $\gamma$-transgenic mice with null CCR5 loci, and the antibody that was used detected an appropriately sized molecule in Western blot evaluations of proteins from lungs from $\mathrm{Tg}^{+}$mice (Figure 2B). In double labeling experiments, confocal analysis demonstrated that, in many cases, CCR5 colocalized with vimentin (see Supplemental Figure 1; supplemental material available online with this article; doi:10.1172/JCI24858DS1). In contrast, CCR5 did not colocalize with CD45, CD3, griffonia lectin, keratin, or S100A4 (Supplemental Figure 1 and data not shown). In keeping with recent reports in other experimental systems (30), these studies demonstrate that IFN- $\gamma$ stimulates the expression of CCR5 on pulmonary interstitial stromal cells.

Role of CCR5 in IFN- $\gamma$-induced inflammation. To understand the roles of MIP-1 $\alpha /$ CCL-3, MIP-1 $\beta / C C L-4$, RANTES/CCL-5, and CCR5 in the generation of IFN- $\gamma$-induced tissue alterations, we
A

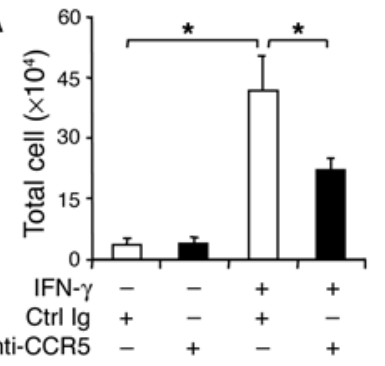

B

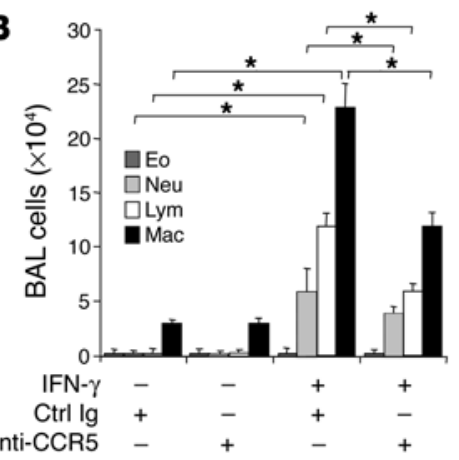

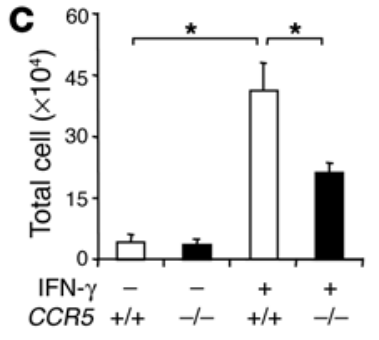

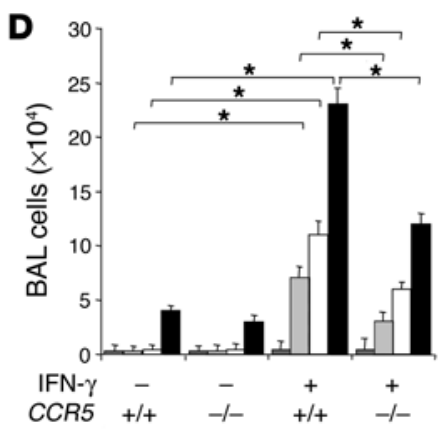


A
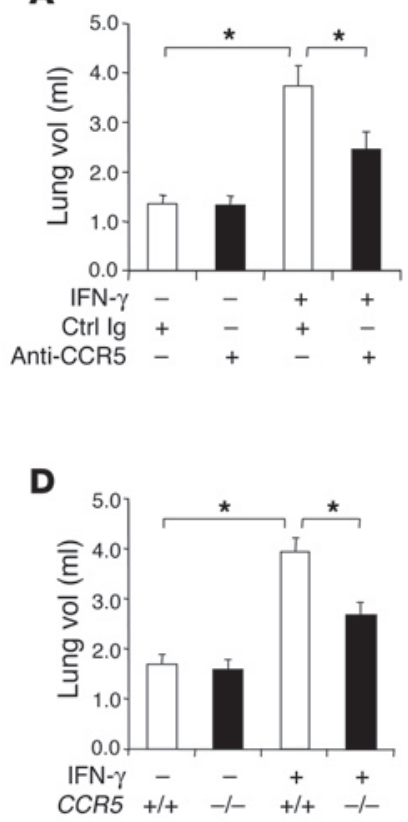

B
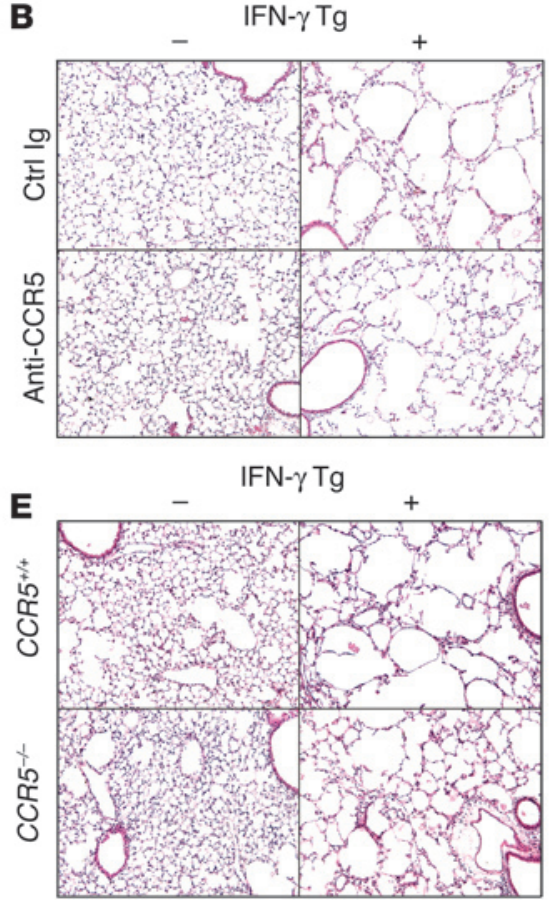

C

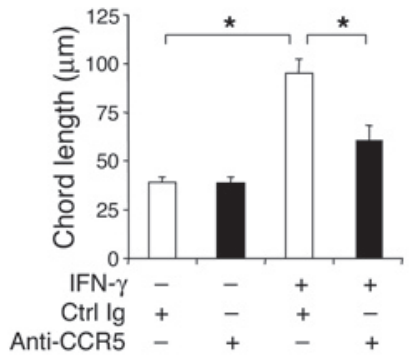

$\mathbf{F}$

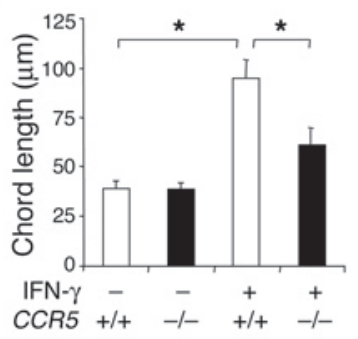

Figure 4

Role of CCR5 in IFN- $\gamma$-induced remodeling. (A-C) $\mathrm{Tg}^{-}$and $\mathrm{Tg}^{+}$mice were placed on dox water and treated with anti-CCR5 or control Ig (Ctrl Ig) for 4 weeks. (D-F) $C C R 5^{+/+}$and $C C R 5^{-/-} \mathrm{Tg}^{-}$and $\mathrm{Tg}^{+}$mice were treated with dox water for 4 weeks. Lung volume (A and $\left.\mathbf{D}\right)$, histology (B and $\mathbf{E} ; \times 10$ ), and chord length ( $\mathbf{C}$ and $\mathbf{F}$ ) were evaluated. $\mathbf{B}$ and $\mathbf{E}$ are representative of a minimum of 5 similar evaluations. The values in the rest of the panels represent the mean \pm SEM of evaluations in a minimum of 5 mice in each group. ${ }^{*} P<0.05$.

compared the inflammation in CC10-rtTA-IFN- $\gamma \mathrm{Tg}^{+}$mice that had been randomized to normal water or dox water at 1 month of age and treated with antiserum against CCR5 or control antiserum. We also bred $\mathrm{Tg}^{+}$mice with $\mathrm{CCR5^{-/ }}$ mice and compared the effects of transgenic IFN- $\gamma$ in $\mathrm{CCR}^{+/+}$and $\mathrm{CCR} 5^{-/-}$mice. As previously reported (19), transgenic IFN- $\gamma$ caused significant increases in bronchoalveolar lavage (BAL) total cell, macrophage, and neutrophil recovery and induced a patchy macrophage-rich tissue inflammatory response (Figure 3 and data not shown). Treatment with anti-CCR5 did not alter the number or differential of the cells that were recovered in BAL fluids and did not alter the tissue histology of lungs from $\mathrm{Tg}^{-}$mice on normal or dox water (Figure 3, $A$ and $B$ and data not shown). In contrast, this intervention significantly decreased BAL total cell and macrophage, neutrophil, and lymphocyte recovery and the tissue inflammatory response in lungs from dox-treated $\mathrm{Tg}^{+}$animals (Figure 3, A and B and data not shown). Similar alterations were seen in comparisons of BAL and tissues from $\mathrm{CCR}^{+/+}$and $\mathrm{CCR} 5^{-/-} \mathrm{Tg}^{+}$mice (Figure 3, $\mathrm{C}$ and D and data not shown). Interestingly, this effect was not specific for IFN- $\gamma$, as a deficiency of CCR5 also decreased LPS-induced pulmonary inflammation (Supplemental Figure 2). Thus, CCR5 is a crucial regulator of the intensity and nature of IFN- $\gamma$-induced pulmonary inflammation.

Role of CCR5 in IFN- $\gamma$-induced alveolar remodeling and destruction. To define the role of CCR5 in the pathogenesis of IFN- $\gamma$-induced alveolar remodeling, we compared the alterations in lung volume, alveolar size, and lung compliance in $\mathrm{Tg}^{+}$mice on dox water that had been treated with anti-CCR5 or control Ig and CCR5 $5^{+/}$and CCR5 $5^{-/-} \mathrm{Tg}^{+}$mice. In accordance with previous observations (19), dox induction of IFN- $\gamma$ caused an impressive increase in all of these parameters (Figure 4 and data not shown). Treatment with anti-CCR5 did not alter these parameters in lungs from wild-type mice on normal or dox water (Figure 4 and data not shown). In contrast, lungs from dox-treated $\mathrm{Tg}^{+}$mice treated with anti-CCR5 were significantly smaller and less compliant than lungs from $\mathrm{Tg}^{+}$mice treated with control Ig (Figure 4A and data not shown). Alveolar size was similarly decreased when assessed with light microscopic or morphometric approaches (Figure 4, B and C). Importantly, similar decreases in alveolar remodeling were noted
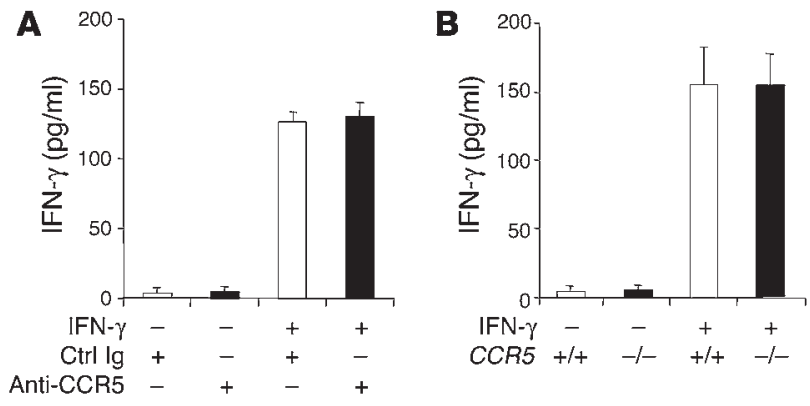

\section{Figure 5}

Role of CCR5 in transgenic IFN- $\gamma$ production. (A) $\mathrm{Tg}^{-}$and $\mathrm{Tg}^{+}$mice were placed on dox water and treated with anti-CCR5 or control Ig for 4 weeks. (B) $C C R 5^{+/+}$and $C C R 5^{-/-} \mathrm{Tg}^{-}$and $\mathrm{Tg}^{+}$mice were treated with dox water for 4 weeks. BAL IFN- $\gamma$ was evaluated by ELISA. The values represent the mean \pm SEM of evaluations in a minimum of 5 mice in each group. 

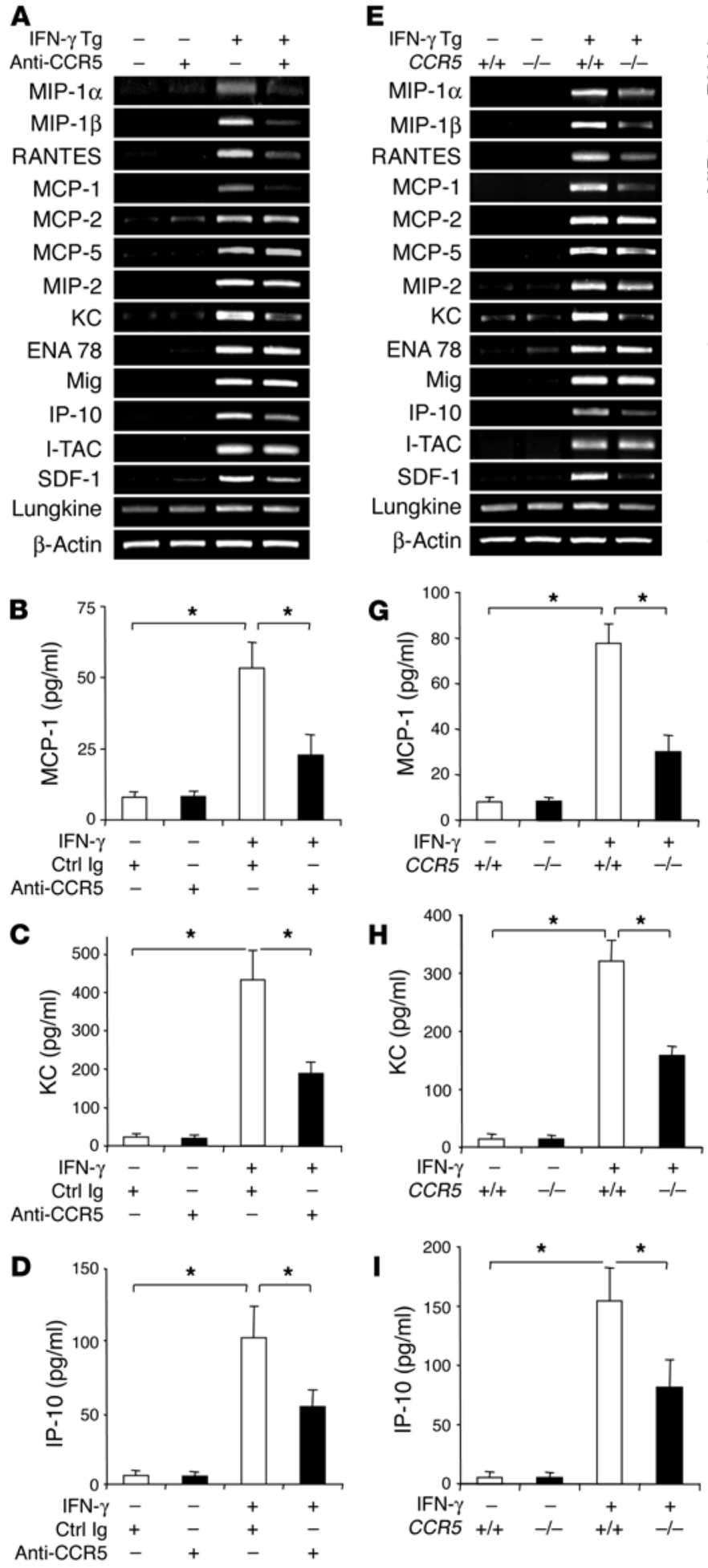
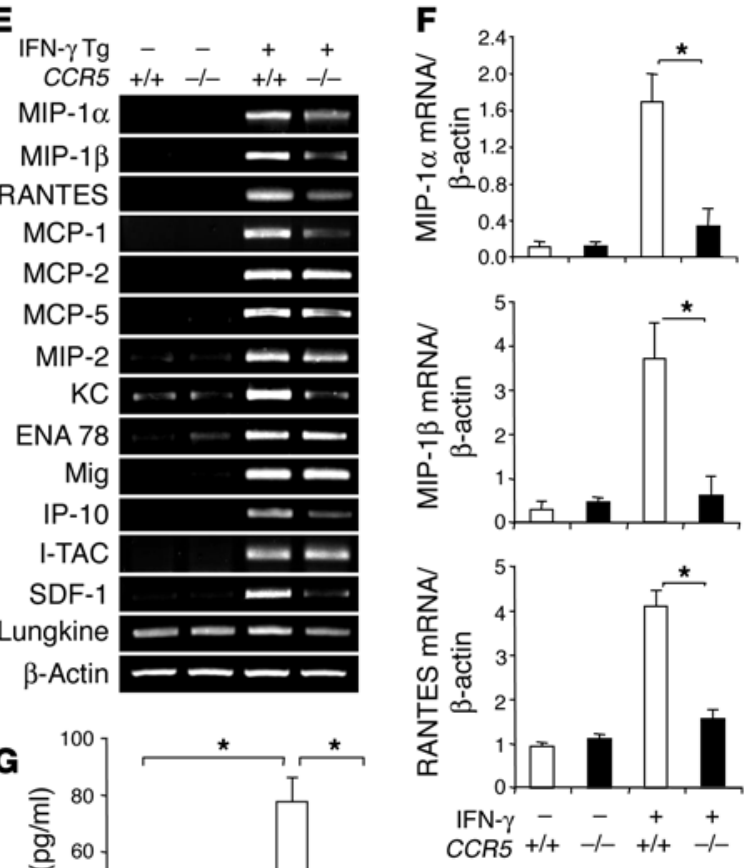

induced alveolar remodeling and destruction in the murine lung.

Role of CCR5 in IFN- $\gamma$ elaboration. A deficiency of CCR5 could modify IFN- $\gamma$-induced tissue responses by altering the production of transgenic IFN- $\gamma$ or modulating IFN- $\gamma$ effector responses. To determine whether alterations in CCR5 regulated the production of IFN- $\gamma$, we compared the levels of BAL IFN- $\gamma$ in $\mathrm{Tg}^{+}$and $\mathrm{Tg}^{-}$ mice treated with anti-CCR5 or control $\mathrm{Ig}$ and $\mathrm{CCR5}^{+/+}$and $\mathrm{CCR5}^{-/-} \mathrm{Tg}^{+}$ mice. IFN- $\gamma$ was not readily apparent in BAL fluids from $\mathrm{Tg}^{-}$mice on normal or dox water that had been treated with anti-CCR5 or control Ig (Figure 5). In contrast, significant levels of BAL IFN- $\gamma$ were observed in $\mathrm{Tg}^{+}$mice on dox water. These levels were similar in mice treated with anti-CCR5 or the control Ig (Figure $5 \mathrm{~A})$. Comparisons of BAL fluids from $\mathrm{CCR5}^{+/+}$and $\mathrm{CCR5}^{-/-} \mathrm{Tg}^{+}$mice also did not reveal differences in IFN- $\gamma$ content (Figure 5B). Thus, treatment with anti-CCR5 and null mutations of CCR5 altered IFN- $\gamma$-induced tissue responses by modifying IFN- $\gamma$ effector pathway activation.

Role of CCR 5 in IFN- $\gamma$-induced chemokine elaboration. To investigate the mechanism(s) by which a deficiency of CCR5 ameliorated IFN- $\gamma$-induced inflammation, we compared the in comparisons of lungs from dox-treated $C C R 5^{+/+}$and CCR5 $5^{-/-}$ $\mathrm{Tg}^{+}$mice (Figure 4, D-F). Overall, treatment with anti-CCR5 or a null mutation of CCR5 caused $52.4 \%$ and $51.3 \%$ decreases in alveolar chord length enlargement, respectively, in dox-treated IFN- $\gamma$-transgenic mice $\left(P<0.01\right.$ compared with $\mathrm{Tg}^{+}$dox-treated controls). When viewed in combination, these studies demonstrate that CCR5 plays a critical role in the pathogenesis of IFN- $\gamma-$ expression of selected chemokines in $\mathrm{Tg}^{+}$mice treated with antiCCR5 or control Ig. As noted above, the levels of MIP-1 $\alpha /$ CCL-3, MIP-1ß/CCL-4, RANTES/CCL-5, MCP-1/CCL-2, MCP-2/ CCL-8, MCP-5/CCL-12, MIP-2/CXCL-2/3, KC/CXCL-1, ENA 78/CXCL-5, Mig/CXCL-9, IP-10/CXCL-10, I-TAC/CXCL-11, and SDF-1/CXCL-12 mRNA and protein were near or below the limits of detection of our assays in $\mathrm{Tg}^{-}$mice and were significantly 

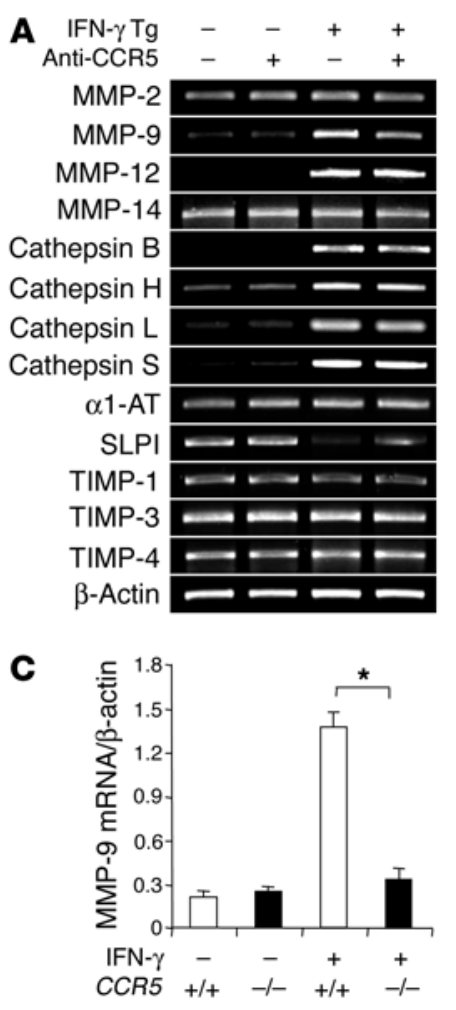

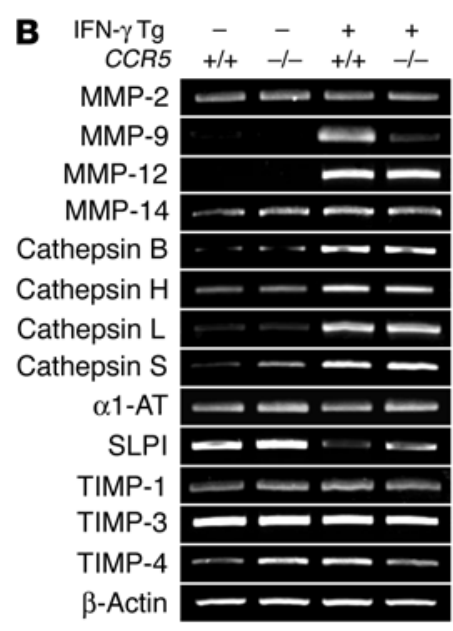

D

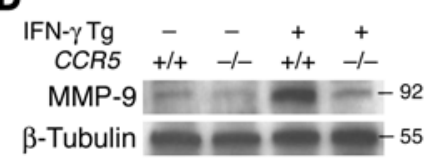

\section{Figure 7}

Role of CCR5 in IFN- $\gamma$-induced protease and antiprotease responses. (A) $\mathrm{Tg}^{-}$and $\mathrm{Tg}^{+}$mice were placed on dox water and treated with anti-CCR5 or control Ig (anti-CCR5-) for 4 weeks. (B-D) $\mathrm{CCR}^{+/+}$and $\mathrm{CCR} 5^{-/-} \mathrm{Tg}^{-}$and $\mathrm{Tg}^{+}$mice were treated with dox water for 4 weeks. Protease and antiprotease mRNAs were evaluated by RT-PCR (A and B), and MMP-9 mRNA and protein were evaluated by real time RT-PCR (C) and Western blotting (D), respectively. Each evaluation is representative of a minimum of 4 similar experiments. $\alpha 1-A T, \alpha-1$ antitrypsin.

(Figure 7, A-C). In these mice, the levels of mRNA encoding a number of these moieties were near or below the limits of detection of our assays. In accordance with previous studies from our laboratory (19), dox induction of IFN- $\gamma$ increased the levels of expression of MMP-9 and -12 and cathepsins B, H, L, and S, while inhibiting the expression of SLPI and not altering the expression of $\alpha 1$-AT or the TIMPs (Figure 7, A-C). The levels of MMP-9 protein were similarly increased (Figure 7D). Interestingly, the neutralization or ablation of CCR 5 decreased the ability of IFN- $\gamma$ to stimulate the accumulation of MMP-9 mRNA and protein and inhibit the expression of SLPI (Figure 7, A-D). It did not, however, alter the effects of IFN- $\gamma$ on the other MMPs, cathepsins, and TIMPs. Thus, IFN- $\gamma$ selectively stimulates MMP-9 and inhibits SLPI via CCR5-dependent activation pathways.

Role of CCR5 in IFN- $\gamma$-induced DNA injury and cell death. In keeping with the proposed role of apoptosis in the pathogenesis of the alveolar remodeling in emphysema (24-28), studies were undertaken to determine whether IFN- $\gamma$ induced DNA injury and apoptosis and define the role(s) of CCR5 in these responses. In these experiments, TUNEL and dual propidium iodide/annexin $\mathrm{V}$ (PI/annexin V) evaluations were used to compare the DNA injury and cell death in lungs from $\mathrm{Tg}^{-}$and $\mathrm{Tg}^{+}$mice that had been treated with either anti-CCR5 or control Ig and $\mathrm{CCR5}^{+/+}$and CCR5 $5^{-1-} \mathrm{Tg}^{+}$mice. In $\mathrm{Tg}^{-}$mice on normal or dox water, $3 \%$ or less of cells were $\mathrm{TUNEL}^{+}$regardless of they type of antibody treatment that was administered (Figure 8, A and B). In contrast, dox induction of IFN- $\gamma$ caused a significant increase in TUNEL staining in lungs from $\mathrm{Tg}^{+}$mice (Figure 8, $\mathrm{A}$ and $\mathrm{B}$ ). This response was seen after as few as 2 days of dox administration. At its peak (after 2 weeks of dox), $15-25 \%$ of cells were $\mathrm{TUNEL}^{+}$. At this time point, TUNEL staining was seen predominantly in alveolar epithelial cells, with lesser numbers of endothelial cells and macrophages manifesting TUNEL reactions (data not shown). Double annexin- $\mathrm{V}$ and PI staining demonstrated that the cell death response in these mice was predominantly apoptosis that manifested as an increase in annexin V staining only (Figure 8C). Significant numbers of cells also manifested increases in annexin $\mathrm{V}$ and PI and were undergoing a response with features of apoptosis and necrosis (Figure 8C). Treatment with anti-CCR5 did not alter the levels of these responses in lungs from $\mathrm{Tg}^{-}$mice on normal or dox water (Figure 8, A and B and data not shown). Treatment with anti-CCR5 did, however, cause a significant decrease in DNA injury and cell death in dox treated $\mathrm{Tg}^{+}$animals (Figure 8, A and $B$ and data not shown). Similar decreases in DNA injury and cell death were seen with TUNEL and dual PI/annexin V evaluations of lungs from dox-treated $C C R 5^{+/+}$and $C C R 5^{-/-} \mathrm{Tg}^{+}$mice (Figure $8, \mathrm{C}-\mathrm{E})$. When viewed in combination, these studies demonstrate that IFN- $\gamma$ is a potent inducer of DNA injury, apoptosis, and a 
A

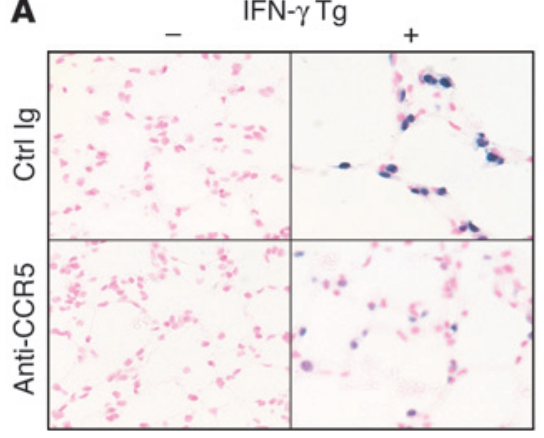

B

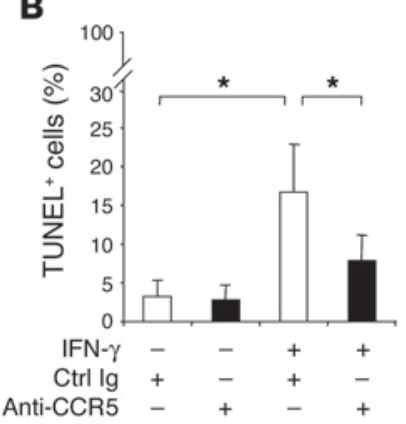

C
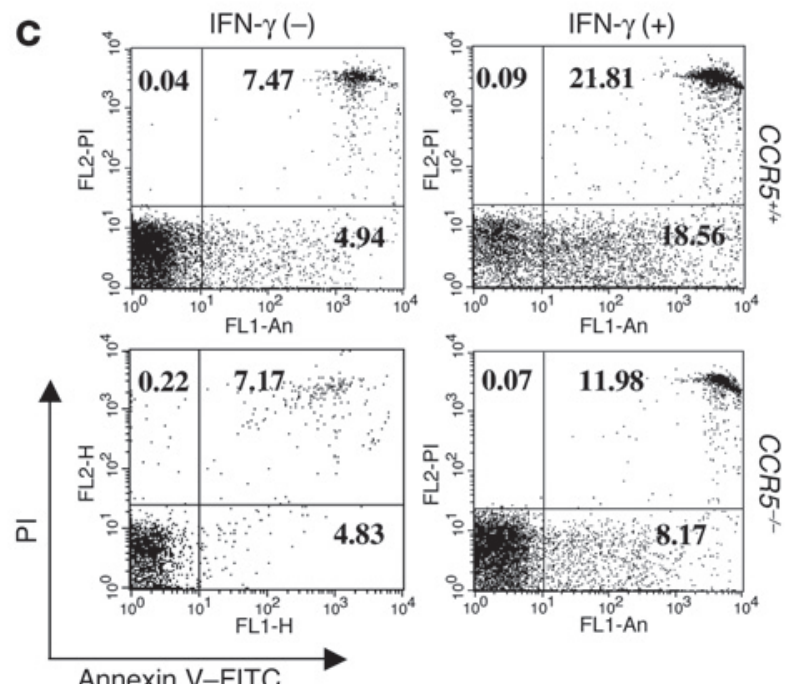

Annexin V-FITC

D

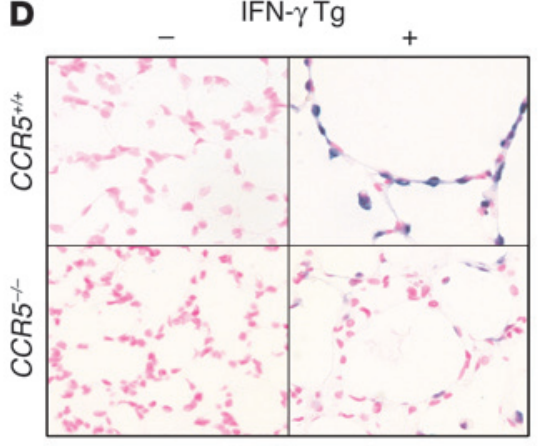

E

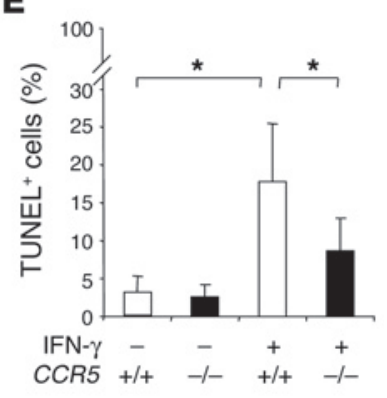

\section{Figure 8}

Role of CCR5 in IFN- $\gamma$-induced DNA injury and cell death. (A and $\mathbf{B}) \mathrm{Tg}^{-}$and $\mathrm{Tg}^{+}$mice were placed on dox water and treated with anti-CCR5 or control Ig for 4 weeks. (C-E) CCR5 $5^{+/+}$ and $\mathrm{CCR} 5^{--} \mathrm{Tg}^{-}$and $\mathrm{Tg}^{+}$mice were treated with dox water for 4 weeks. TUNEL evaluations ( $A$ and $\mathbf{D} ; \times 40$ ), TUNEL quantification (B and $\mathbf{E}$ ), and dual Pl/annexin V evaluations (C) were undertaken. Each evaluation in $\mathbf{A}, \mathbf{C}$, and $\mathbf{D}$ is representative of a minimum of 4 similar experiments. The values in the remaining panels represent the mean \pm SEM of evaluations in a minimum of 4 animals. ${ }^{*} P<0.05$.

caspase- $3,-8$, and -9 and Bid, causing readily detectable increases in caspase bioactivities and truncated Bid (tBid) accumulation (Figure 9, F and G). In all cases, these events were CCR5 dependent, as anti-CCR5 treatment or a null mutation of CCR5 decreased the levels of mRNA encoding Fas, FasL, TNF- $\alpha$, caspase- $3,-8$, and -9 , Bid, and Bax, the levels of TNF- $\alpha$ protein, and caspase and Bid activation (Figure 9). When viewed in combination, these studies demonstrate that IFN- $\gamma$ is a potent activator of the extrin$\mathrm{sic} /$ death receptor and intrinsic/mitochondrial apoptosis pathways and that these activation events are, at least in part, CCR5 dependent.

Role of CCR5 in cigarette smoke-induced inflammation and alveolar remodeling. The studies noted above demonstrate that CCR5 plays a key role in the pathogenesis of IFN- $\gamma$ induced inflammation and emphysema. Since human pulmonary emphysema is often caused by cigarette smoke exposure (20), studies were undertaken to define the role of CCR5 in the pathogenesis of cigarette smoke-induced emphysema. Studies were first undertaken to determine whether IFN- $\gamma$ plays an important role in cigarette smokeinduced emphysema and stimulates the production of CCR5 ligand chemokines. In these experiments we first compared the emphysema induced by cigarette smoke in wild-type and IFN- $\gamma$-null mice. As can be seen in Figure $10 \mathrm{~A}$, cigarette smoke caused notable emphysema in wildtype mice. Importantly, this emphysematous response was significantly ameliorated in the IFN- $\gamma$-null animals (Figure 10A). In additional experiments, we measured the levels of CCR5 ligand chemokines in BAL fluids from cigarette smoke- and room air-exposed mice. These experiments demonstrated that cigarette smoke stimulates MIP- $1 \alpha / C C L-3$, MIP-1 $\beta / C C L-4$, and RANTES/CCL-5 in mixed apoptosis/necrosis cellular response. They also demonstrate that these responses are mediated by pathways that are, at least partially, CCR5-dependent.

Contributions of CCR5 to IFN- $\gamma$-induced apoptosis. To further understand the mechanisms by which CCR5 regulated DNA injury and cell death, the expression and activity of caspases and key cell death regulators were evaluated in mice that were treated with anti-CCR5 or control Ig and CCR5 ${ }^{+/+}$and CCR5 $5^{-/-} \mathrm{Tg}^{+}$mice. The levels of mRNA encoding Fas, FasL, TNF- $\alpha$, caspase-3, -8, and - 9 , $\mathrm{Bid}$, and $\mathrm{Bax}$ in $\mathrm{Tg}^{-}$mice were at or near the limits of detection in our assays and were not significantly altered by CCR5 neutralization or ablation (Figure 9, A-C). IFN- $\gamma$ was a potent stimulator of these moieties that increased the levels of Fas, FasL, TNF- $\alpha$, caspase-3, $-8,-9$, and Bid and Bax mRNA and the levels of TNF- $\alpha$ protein (Figure 9, A-E and data not shown). IFN- $\gamma$ also activated the murine lung (Figure 10B).

Because cigarette smoke induction of emphysema was IFN- $\gamma$ dependent and associated with the induction of CCR5 ligands, we next evaluated the roles of CCR5 in these responses. This was done by comparing the responses in wild-type and CCR5-null mice that were chronically exposed to cigarette smoke or room air. In these studies, cigarette smoke caused a macrophage-rich BAL and tissue inflammatory response. This response was most prominent after 2 months of smoke exposure and persisted throughout the 6-month exposure interval (Figure 10, C and D and data not shown). It also caused DNA injury/apoptosis that could be observed with TUNEL evaluations (Figure 10E) and histologically and morphometrically apparent emphysema (Figure 10, F and G). In all cases, these responses were CCR5 dependent, since tissue and BAL inflammation, TUNEL staining, and emphysema were all decreased in ciga- 

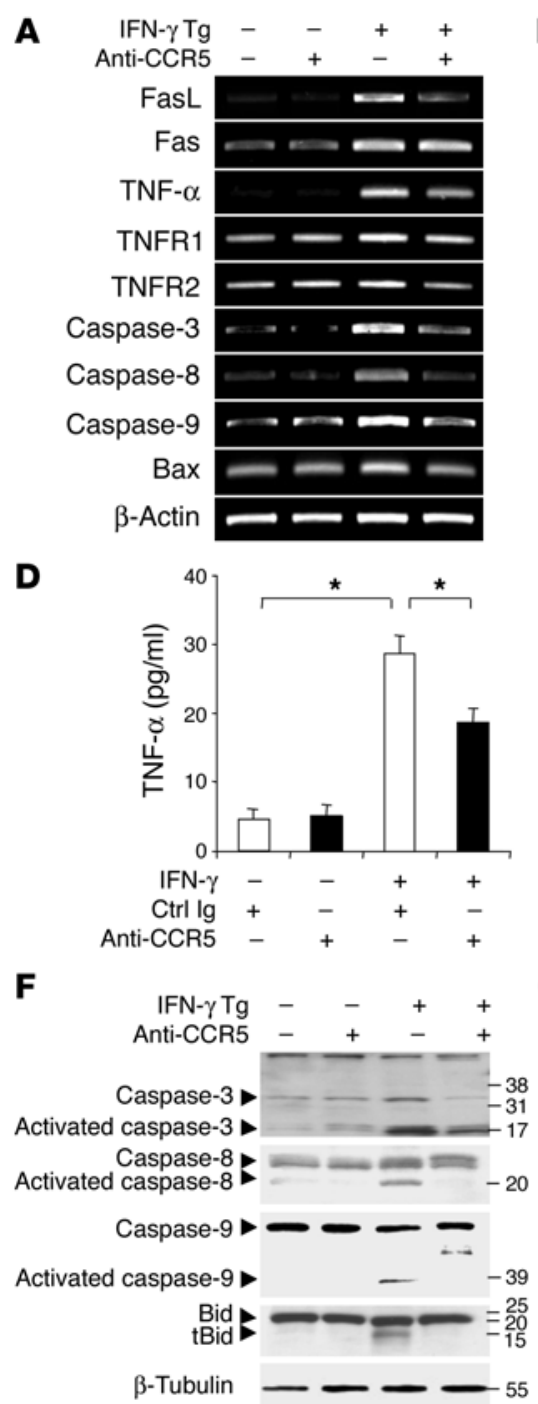
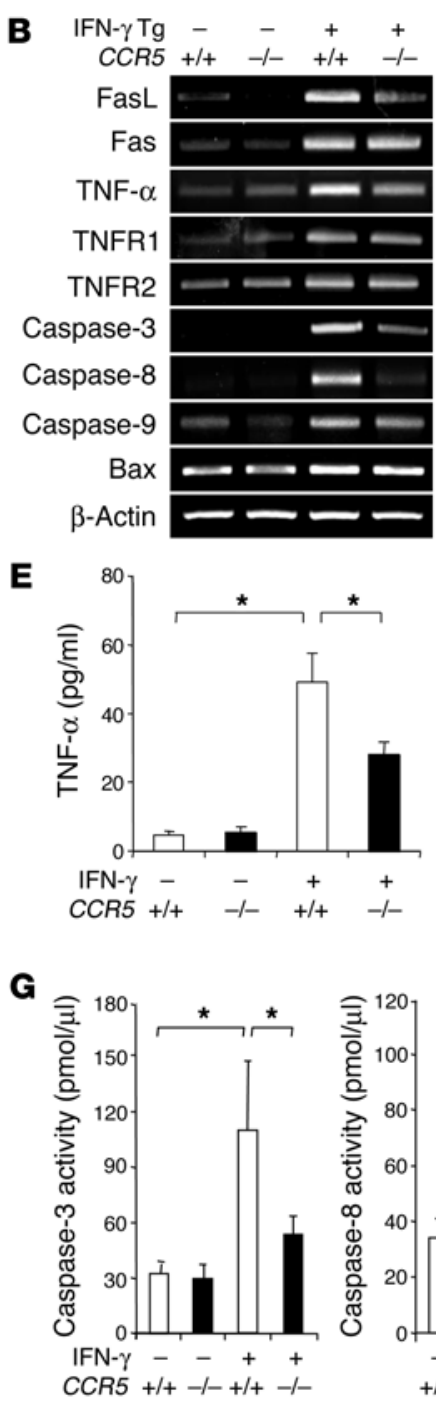
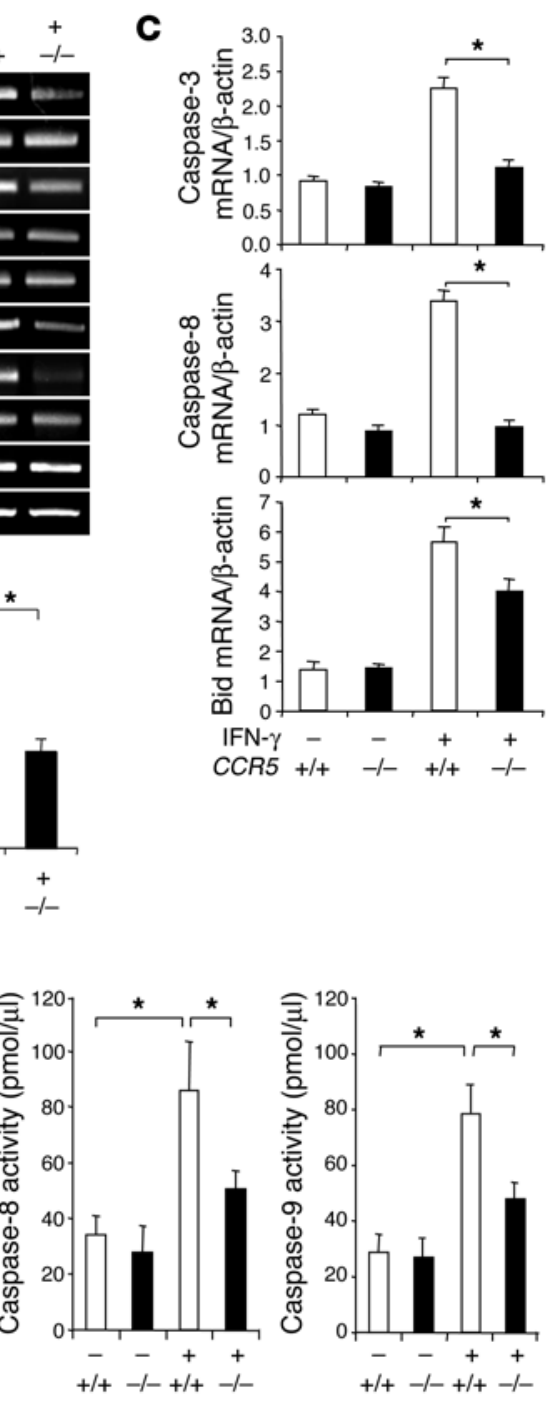

\section{Figure 9}

Role of CCR5 in IFN- $\gamma$ regulation of cell death pathways. (A, D, and F) $\mathrm{Tg}^{-}$and $\mathrm{Tg}^{+}$mice were placed on dox water and treated with anti-CCR5 or control lg. (B, C, E, and G) CCR5 $5^{+/}$and $C C R 5^{-/-} \mathrm{Tg}^{-}$and $\mathrm{Tg}^{+}$mice were treated with dox water for 4 weeks. mRNA was evaluated by RT-PCR (A and B) and real-time RT-PCR (C). BAL TNF levels were evaluated by ELISA (D and E). (F) Caspase-3, -8, and -9, Bid, and truncated Bid (tBid) were evaluated by Western blot analysis. (G) Caspase bioactivity was evaluated. Each evaluation in $\mathbf{A}, \mathbf{B}$, and $\mathbf{F}$ is representative of a minimum of 4 similar experiments. The values in the remaining panels represent the mean \pm SEM of evaluations in a minimum of 5 animals. ${ }^{*} P<0.05$.

rette smoke-exposed CCR5 $5^{-/-}$and $C C R 5^{+/+}$mice (Figure $10, \mathrm{C}-\mathrm{G}$ and data not shown). These studies demonstrate that CCR5 plays a critical role in cigarette smoke-induced chemokine induction, inflammation, DNA injury/apoptosis, and alveolar remodeling.

\section{Discussion}

To further understand the cellular and molecular events involved in IFN- $\gamma$-induced phenotype generation, we took advantage of a transgenic system developed in our laboratory in which IFN- $\gamma$ effector pathways can be selectively assessed in vivo and used this system to characterize the chemokine response that is induced by IFN- $\gamma$ in this setting. These studies demonstrate that IFN- $\gamma$ is a potent inducer of a number of CXC and CC chemokines. Prominent on this list are the CCR5 ligands RANTES/CCL-5, MIP-1 $\beta / C C L-4$, and MIP- $1 \alpha / C C L-3$. These effects were not specific for these moi- eties, as IFN- $\gamma$ also stimulated the production of MCP-1/CCL-2, MCP-2/CCL-8, MCP-5/CCL-12, MIP-2/CXCL-2/3, KC/CXCL-1, ENA 78/CXCL-5, Mig/CXCL-9, IP-10/CXCL-10, I-TAC/CXCL-11, SDF-1/CXCL-12, C10/CCL6, MDC/CCL22, and TECK/CCL25. These effects were, however, at least partially specific, as eotaxin/ CCL-11, TARC/CCL-17, and lungkine/CXCL-15 were not similarly regulated. Importantly, these studies also demonstrate that interventions that neutralize or abrogate CCR5 diminish the ability of IFN- $\gamma$ to induce inflammatory, DNA injury, cell death, and remodeling responses in the murine lung. They also define the chemokine cascades, protease and antiprotease alterations, and apoptosis regulatory events that are dependent on CCR5 in these responses. When viewed in combination, these studies provide insights into the pathogenesis and complexity of IFN- $\gamma$-induced inflammatory and remodeling responses in the setting of type I tissue reactions. 

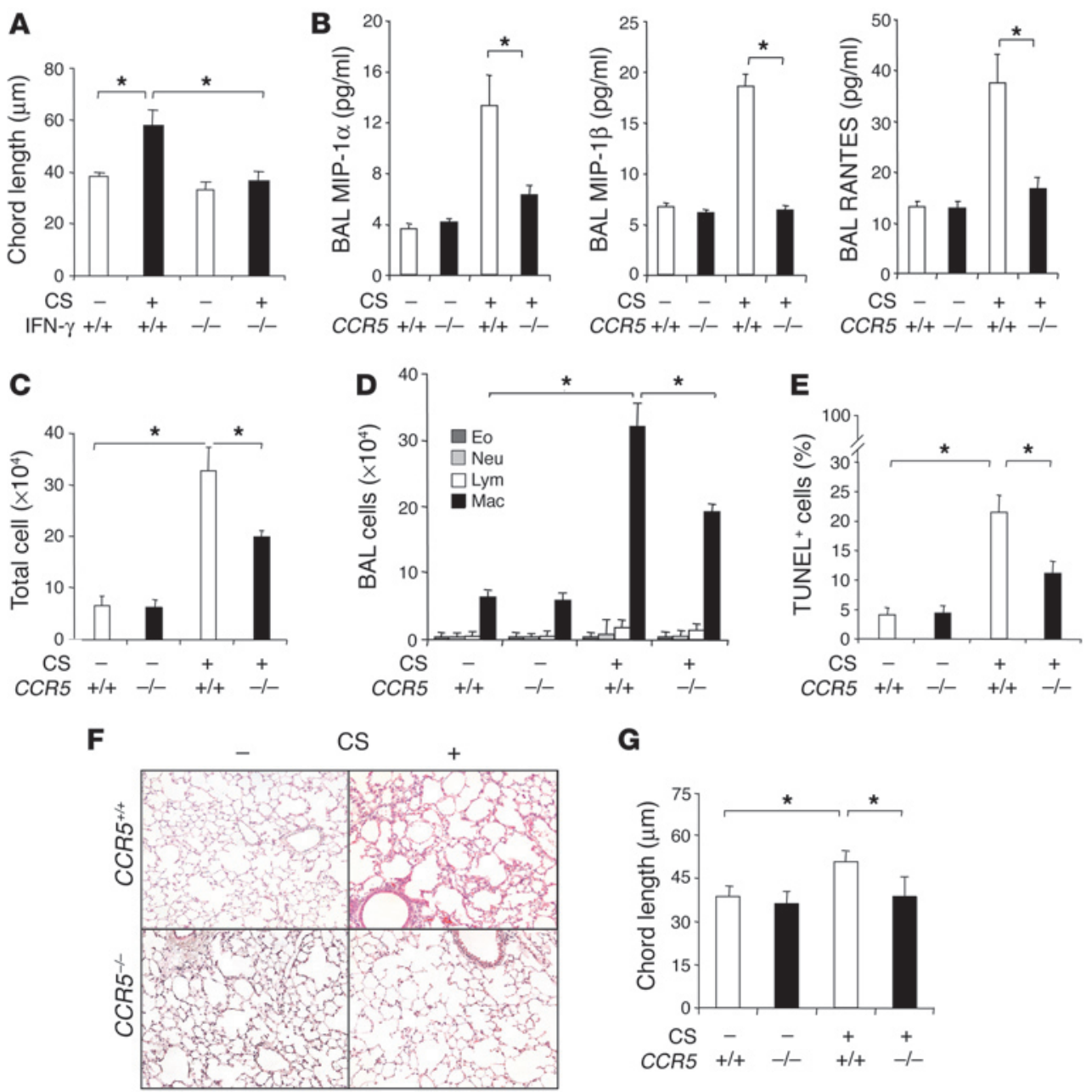

G

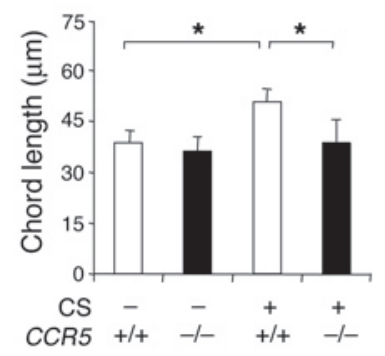

\section{Figure 10}

Role of IFN- $\gamma$ and CCR5 in cigarette smoke-induced responses. (A) IFN- $\gamma^{+/+}$and IFN- $\gamma^{-/-}$mice were exposed to cigarette smoke (CS) for 6 months. (B-G) $\mathrm{Tg}^{-}$mice with wild-type and null CCR5 loci were exposed to cigarette smoke for 2 (B-E) or 6 (F and $\mathbf{G}$ ) months. Alveolar chord length (A and $\mathbf{G}$ ); BAL RANTES/CCL-5, MIP-1 $\alpha / C C L-3$, and MIP-1 $\beta / C C L-4$ (B); total BAL cell recovery $(\mathbf{C})$; the differential distribution of the recovered BAL cells (D); TUNEL staining (E); and alveolar histology $(\mathbf{F} ; \times 10)$ were assessed. Each evaluation in $\mathbf{F}$ is representative of a minimum of 4 similar experiments. The values in the remaining panels represent the mean \pm SEM of evaluations in a minimum of 4 animals. ${ }^{*} P<0.05$.
Chemokines are small cytokines $(44,45)$ that have been subdivided into CXC, CC, C, and CXXC families based on sequence considerations. The $\mathrm{CC}$ and $\mathrm{CXC}$ chemokine groups are large and contain more than 50 identified ligands. Although in vitro characterization would suggest that there is impressive redundancy in this system, examinations in vivo have demonstrated that their production is often organized in a coordinated manner and that their effector functions can be restricted to different stages of disease development and/or pathology (44-48). Thus, in vivo, a deficiency of an individual ligand or its receptor can cause striking alterations in tissue phenotype. Our studies demonstrate that, although IFN- $\gamma$ is a potent stimulator of a wide variety of CC and $\mathrm{CXC}$ chemokines, the selective neutralization and/or ablation of CCR5 caused an impressive decrease in IFN- $\gamma$-induced inflammation and tissue remodeling responses. One could hypothesize that this previously unappreciated relationship between IFN- $\gamma$ and CCR5 is the result of the amelioration of the stimulatory effects of RANTES/CCL-5, MIP-1 $\alpha / C C L-3$, and/or MIP-1 $\beta / C C L-4$. Our studies, however, demonstrate that this is only part of the mechanism. Specifically, they demonstrate that CCR5 signaling plays a critical role in, and is required for, an optimal IFN- $\gamma$-induced chemokine response, with the induction of MCP-1/CCL-2, MIP-1 $\alpha /$ CCL-3, MIP-1 $\beta / C C L-4$, MIP-2/CXCL-2/3, RANTES/CCL-5, KC/ CXCL-1, Mig/CXCL-9, SDF-1/CXCL-12, and IP-10/CXCL-10 being mediated by a CCR5-dependent mechanism. Cigarette smoke induction of RANTES/CCL-5, MIP- $1 \alpha /$ CCL-3, and MIP- $1 \beta$ / CCL-4 was also shown to be CCR5 dependent. Interestingly, CCR5 signaling did not contribute to the induction by IFN- $\gamma$ of a variety of other chemokines, including MCP-2/CCL-8, MCP-5/CCL-12, Mig/CXCL-9, and I-TAC/CXCL-11. These studies highlight, for the first time to our knowledge, the ability of CCR5 to contribute to the autoinduction of its own ligands, RANTES/CCL-5, MIP-1 $\alpha / C C L-3$, and MIP-1 $\beta / C C L-4$. They also highlight, for the first time to our knowledge, the existence of a CCR5-dependent chemokine cascade that contributes to the induction, intensity, and character of IFN- $\gamma$-induced and cigarette smoke-induced tissue inflammatory and remodeling responses.

Although 18 million people in the United States and millions more worldwide suffer from emphysema, the mechanisms of emphysematous alveolar remodeling and destruction are poorly understood. In keeping with the belief that Tc1 responses contribute to the pathogenesis of pulmonary emphysema, a CD8 cell-, mononuclear cell-, and neutrophil-rich inflammatory response has been noted in tissues from patients with $\operatorname{COPD}(18,20,49-51)$, and previous studies from our laboratory demonstrated that the prototypic Th $1 / \mathrm{Tc} 1$ cytokine IFN- $\gamma$ induces pulmonary emphysema when expressed in the murine lung (19). In the present studies, we add to this understanding by demonstrating that CCR5 plays 


\section{Table 1}

RT-PCR primers, conditions, and products

\begin{tabular}{|c|c|c|c|}
\hline \multicolumn{4}{|l|}{ RT-PCR } \\
\hline Gene & S/AS & Primer sequence $\left(5^{\prime}\right.$ to $\left.3^{\prime}\right)$ & Product (bp) \\
\hline $\mathrm{CxCl1}$ & $S$ & CTGGGATTCACCTCAAGAACAT & 173 \\
\hline \multirow[t]{2}{*}{$\mathrm{Cxc} / 5$} & $\begin{array}{l}\text { AS } \\
S\end{array}$ & CTGCCCCTTCCTCAGTCATA & 249 \\
\hline & AS & GTGCATTCCGCTTAGCTTTC & \\
\hline \multirow[t]{2}{*}{$\mathrm{Cxc} / 9$} & $S$ & TCTTCCTGGAGCAGTGTGG & 196 \\
\hline & AS & TCCGGATCTAGGCAGGTTT & \\
\hline \multirow[t]{2}{*}{ Cxcl10 } & $\mathrm{S}$ & AAGTGCTGCCGTCATTTTCT & 186 \\
\hline & AS & GTGGCAATGATCTCAACACG & \\
\hline \multirow[t]{2}{*}{ Cxcl12 } & $S$ & GCTCTGCATCAGTGACGGTA & 184 \\
\hline & AS & TAATTTCGGGTCAATGCACA & \\
\hline \multirow[t]{2}{*}{ Cxcl11 } & $S$ & CTGCTCAAGGCTTCCTTATGTT & 167 \\
\hline & AS & CCTTTGTCGTTTATGAGCCTTC & \\
\hline \multirow[t]{2}{*}{ Cxcl15 } & S & CGTCCCTGTGACACTCAAGA & 205 \\
\hline & AS & TAATTGGGCCAACAGTAGCC & \\
\hline
\end{tabular}

S, sense; AS, antisense.

a key role in Th1-induced and cigarette smoke-induced remodeling responses in the lung. By demonstrating that interventions that neutralize and or ablate CCR5 only partially abrogate these responses, we also highlight the CCR5-dependent and -independent mechanisms that are operative in these settings. Last, we provide insights into the multiple mechanisms that CCR5 may use in this setting. Specifically, the protease-antiprotease hypothesis suggests that alveolar destruction is induced in the lung by an increase in proteases and/or a decrease in antiproteases (20). In accordance with this concept, our studies demonstrate that the decrease in IFN- $\gamma$-induced remodeling that is seen after CCR5 neutralization and/or ablation is associated with a decrease in the expression of MMP-9 and an increase in the expression of the antiprotease SLPI. Most recently, structural cell apoptosis has been proposed to contribute to the pathogenesis of pulmonary emphysema (24-28). In accordance with this concept, our studies demonstrate that transgenic IFN- $\gamma$ is a potent inducer of epithelial cell apoptosis and that this response is mediated via a mechanism that is, at least in part, CCR5 dependent. Recent studies have also demonstrated that CCR5 ligands are impressively potent stimulators of CD8 cell migration (52). In combination, these studies demonstrate that CCR5 signaling contributes to IFN- $\gamma$-induced inflammatory, proteolytic, antiprotease, DNA injury, and cell death responses in the lung. Our demonstration that cigarette smoke causes emphysema via an IFN- $\gamma$-dependent mechanism and that null mutations of CCR5 diminish the inflammatory and remodeling alterations that are induced by chronic cigarette smoke inhalation further support the relevance of our transgenic studies and our CCR5-based investigations to human COPD. These studies provide what we believe to be the first mechanistic link between inflammation and apoptosis in COPD and, when combined with our transgenic studies, demonstrate that IFN- $\gamma$ is necessary and sufficient to induce pulmonary emphysema. When viewed in combination, they also suggest that interventions that alter CCR5-ligand binding and/or CCR5 signaling may be therapeutically useful in the treatment of this often-times devastating disorder.

Although cell death can be triggered by a vast array of stimuli and mediated via an increasingly complex series of pathways, the vast majority of signals engage the cell death machinery at the level of the cell membrane or at the level of the mitochondria. The membrane ("extrinsic") pathway triggers cell surface "death receptors" such as Fas, which bind FasL, and TNF receptor 1 (TNFR1), which binds TNF and lymphotoxin and subsequently activate caspase-8. Other stimuli use mitochondrial dysfunction to signal death responses. In this "intrinsic" response, $\mathrm{BH} 3$ domain-only family members such as Bid are activated to $\mathrm{BBid}$ and interact with Baxtype proteins to form or interact with mitochondrial pores, release cytochrome $c$, activate caspase- 9 , and induce cell death $(53,54)$. Thus, to further understand the mechanism(s) by which CCR5 regulates IFN- $\gamma$-induced cell death responses, we characterized the intrinsic and extrinsic pathways in mice treated with anti-CCR5 or control Ig and mice with wild-type and null CCR5 loci. These studies demonstrate that IFN- $\gamma$ activates both the intrinsic and extrinsic cell death pathways. They also demonstrate that CCR5 contributes to these responses in a variety of ways, including regulating the levels of mRNA encoding Fas, FasL, TNF, TNFR1, TNFR2, caspases, $\mathrm{Bid}$, and Bax; the levels of TNF protein; and the activation and bioactivity of caspase- $3,-8$, and -9 and Bid. These are the first studies to our knowledge to demonstrate a prominent role for CCR5 in the regulation of IFN- $\gamma$-induced cell death responses and the first to demonstrate a prominent role of CCR5 in structural cell apoptosis. These observations, however, are not without precedent, as CCR5 has been shown to be a coreceptor for HIV, where it activates Fas and caspase- 8 and induces CD4 cell death (42). They also agree with the recent demonstration that, in contrast to Th2 responses, Th1 granulomatous responses are preferentially associated with the induction of genes that are involved in tissue injury and apoptosis (4). It is clear from these studies that CCR5 is a multifunctional regulator of IFN- $\gamma$-induced apoptotic and necrotic responses in the lung. Our demonstration that CCR5-null mice are protected from the DNA injury and cell death induced by cigarette smoke further substantiates the disease relevance of these findings in Th1/Tc1 responses and oxidant injury states.

In summary, these studies demonstrate that IFN- $\gamma$ is a potent stimulator of a variety of CC and CXC cytokines, including the CCR5

\section{Table 2}

Real-time RT-PCR primers, conditions, and products

\begin{tabular}{|c|c|c|c|}
\hline Genes & S/AS & Primer sequence $\left(5^{\prime}\right.$ to $\left.3^{\prime}\right)$ & Product (bp) \\
\hline \multirow[t]{2}{*}{ Cc/3 } & $S$ & TATTTTGAAACCAGCAGCCTTT & 103 \\
\hline & AS & ATTCTTGGACCCAGGTCTCTTT & \\
\hline \multirow[t]{2}{*}{ Ccl4 } & $S$ & TCCTGCTGTTTCTCTTACACCTC & 113 \\
\hline & AS & CCTCTTTTGGTCAGGAATACCA & \\
\hline \multirow[t]{2}{*}{ Ccl5 } & S & ATATGGCTCGGACACCACTC & 131 \\
\hline & AS & TCCTTCGAGTGACAAACACG & \\
\hline \multirow[t]{2}{*}{ Mmpg } & $S$ & CAATCCTTGCAATGTGGATG & 130 \\
\hline & AS & AGTAAGGAAGGGGCCCTGTA & \\
\hline \multirow[t]{2}{*}{ Casp3 } & $S$ & ATGGGAGCAAGTCAGTGGAC & 137 \\
\hline & AS & CGTACCAGAGCGAGATGACA & \\
\hline \multirow[t]{2}{*}{ Casp8 } & $S$ & CTTCGAGCAACAGAACCACA & 102 \\
\hline & AS & TTCTTCACCGTAGCCATTCC & \\
\hline \multirow[t]{2}{*}{ Bid } & $S$ & CTGCCTGTGCAAGCTTACTG & 142 \\
\hline & AS & GTCTGGCAATGTTGTGGATG & \\
\hline \multirow[t]{2}{*}{ Actb } & $S$ & AGAGGGAAATCGTGCGTGAC & 137 \\
\hline & AS & CAATAGTGATGACCTGGCCGT & \\
\hline \multirow[t]{2}{*}{ Ccr5 } & $S$ & ATTCTCCACACCCTGTTTCG & 388 \\
\hline & AS & GTTCTCCTGTGGATCGGGTA & \\
\hline
\end{tabular}


ligands RANTES/CCL-5, MIP-1 $\alpha /$ CCL-3, and MIP-1 $\beta /$ CCL-4. They also demonstrate that CCR5 plays a critical role in the generation of IFN- $\gamma$-induced inflammation, DNA injury, cell death, and tissue remodeling and illustrate important CCR5-dependent pathways that IFN- $\gamma$ uses to stimulate chemokines, proteases, antiproteases, and the intrinsic and extrinsic cell death pathways. Dysregulated Th1 inflammation and exaggerated IFN- $\gamma$ production are prominent findings in emphysema and a wide variety of other disorders, including diabetes, atherosclerosis (2), Crohn disease (3), Schistosoma infection (4), coeliac disease (5), rheumatoid arthritis (6) periodontitis (7), Bechet disease (8), aphthous ulcers (9), autoimmune gastritis (10), and uveoretinitis (11). Our studies suggest that IFN- $\gamma$ contributes to the genesis of the inflammation and tissue destruction that are seen in these settings and that these responses are mediated, at least in part, by a CCR5-dependent pathway. These studies also suggest that interventions that block the activation and/or signaling of CCR5 may be therapeutic in these disorders. Additional investigation of the roles of CCR5 in the pathogenesis of these diseases and the utility of CCR5-based interventions and therapeutics in their treatment is warranted.

\section{Methods}

Transgenic and genetically modified mice. CC10-rtTA-IFN- $\gamma$ mice that had been generated in our laboratory were used in these studies (19). These are dual transgene-positive animals in which the reverse tetracycline transactivator (rtTA) drives the expression of the murine IFN- $\gamma$ gene in a lung-specific and externally regulatable fashion. The transgene in these mice was activated by adding dox to the animals' drinking water. On a BALB/c background, these mice get emphysema after 2-4 weeks of dox administration. On a C57BL/6 background, these mice get emphysema after $4-6$ weeks on dox. Thus, mice bred for at least 10 generations onto a $\mathrm{BALB} / \mathrm{c}$ or $\mathrm{C} 57 \mathrm{BL} / 6$ background were employed. These mice were maintained as dual transgene $(+)$ heterozygotes (referred to as $\mathrm{Tg}^{+}$). The details of both genetic constructs, the methods of microinjection and genotype evaluation, the inducibility and the emphysematous and inflammatory phenotype of CC10-rtTA-IFN- $\gamma$ mice have been previously described (19).

CCR5-null mutant (-/-) mice, generated by W. Kuziel and colleagues (55), were obtained from The Jackson Laboratory after breeding for more than 10 generations onto a C57BL/6 background. $\mathrm{CCR} 5^{+/+}$or CCR5 $5^{-/-} \mathrm{CC} 10-$ rtTA-IFN- $\gamma$ mice were generated by breeding C57BL/ 6 background IFN- $\gamma-$ overexpressing mice with the CCR $5^{-/-}$animals. PCR was used to define the transgenic status of all offspring, using primers that detected rtTA and/or the junction region of the murine IFN- $\gamma$-human growth hormone construct. The CCR5 loci were evaluated by PCR using primers: upper, $5^{\prime}$ ATTCTCCACACCCTGTTTCG-3' and lower, 5'-GTTCTCCTGTGGATCGGGTA-3', which detect a 388-bp reaction product. All animal protocols were approved by the Institutional Animal Care and Use Committee of Yale University School of Medicine.

Dox water administration. CC10-rtTA-IFN- $\gamma$ mice and littermate controls were maintained on normal water until they were 4-6 weeks old. They were then randomized to normal or dox water as previously described (19).

Immunologic interventions. Four- to 6-week-old $\mathrm{BALB} / \mathrm{c} \mathrm{Tg}^{-}$and $\mathrm{Tg}^{+}$ mice were randomized to receive rat monoclonal anti-CCR5 (Research Diagnostics Inc.) or an isotype control (rat IgG2c) Ig (control Ig) (500 $\mu \mathrm{g}$ i.p. every other day). Two days later they were randomized to normal or dox water and maintained on this regimen for 10 days. At the end of this interval, the animals were sacrificed, and pulmonary phenotype was assessed as described below.

$B A L$ and quantification of IFN- $\gamma$. Mice were euthanized, the trachea was isolated by blunt dissection, and tubing was secured in the airway. Three vol- umes of $0.6 \mathrm{ml}$ of PBS were then instilled and gently aspirated and pooled. Each BAL fluid sample was centrifuged, and the supernatants were stored at $-70^{\circ} \mathrm{C}$ until used. The levels of IFN- $\gamma$ were determined using a commercial ELISA (R\&D Systems Inc.) as per the manufacturer's instructions.

Histologic analysis. Animals were anesthetized, a median sternotomy was performed, and right heart perfusion was accomplished with calcium- and magnesium-free PBS to clear the pulmonary intravascular space. The lungs were then fixed to pressure $(25 \mathrm{~cm})$ with neutral buffered $10 \%$ formalin, fixed overnight in $10 \%$ formalin, embedded in paraffin, sectioned, and stained. H\&E stains were performed in the Research Histology Laboratory of the Department of Pathology at Yale University School of Medicine.

LPS administration. BAL was performed on wild-type and CCR5-null mice 6 hours after nasal application and aspiration of LPS $(20 \mu \mathrm{g} / \mathrm{ml}$ or $1 \mu \mathrm{g} / \mathrm{ml}$ ) (Escherichia coli serotype 0.55:B5; Sigma-Aldrich) or the appropriate vehicle control.

$m R N A$ analysis. mRNA levels were assessed using RT-PCR and real-time RT-PCR as previously described by our laboratory (19, 56-58). In these assays, gene-specific primers were used to amplify selected regions of each target moiety. The primers for targeted genes that were not described in prior publications are detailed in Tables 1 and 2 .

Chemokine measurements. The levels of selected chemokines in BAL fluids were evaluated by ELISA using commercial assays (R\&D Systems) as described by the manufacturer.

Lung volume, morphometric, and compliance assessment. Lung volume, alveolar size, and lung compliance were assessed via volume displacement and morphometric chord length assessments as previously described $(19,57,58)$. In brief, the trachea was cannulated, the lungs were degassed, and the lungs and heart were removed en bloc and inflated with PBS at $25 \mathrm{~cm}$ of pressure. The size of the lung was evaluated via volume displacement. Compliance was calculated as the change in volume divided by the change in pressure. Alveolar size was estimated from the mean chord length of the airspace.

CCR5 immunohistochemistry. For tissue staining, lungs were fixed in Streck Tissue Fixative (Streck Inc.) and embedded in paraffin. Sections were deparaffinized, and if needed, antigen retrieval was performed as described below. Slides were then blocked with an avidin/biotin blocking kit (DakoCytomation) as per the manufacturer's instructions and incubated in 5\% normal horse serum/PBS for 20 minutes, and the primary antibodies were applied overnight at $4^{\circ} \mathrm{C}$. For 2 -color staining, the antibodies were mixed together and then applied to the slide. Antibodies used include goat antiCCR5 (catalog M-20; Santa Cruz Biotechnology Inc.), mouse anti-vimentin (clone V9; DakoCytomation), rat anti-CD45 (BD Biosciences - Pharmingen), rabbit anti-keratin (catalog Z0622; DakoCytomation), anti-CD3 (BD Biosciences - Pharmingen), S100A4 (BD Biosciences - Pharmingen), and biotinylated Griffonia Simplicifolia GSI-B4 lectin (Vector Laboratories). For staining with anti-CCR5 or GSI-B4, no antigen retrieval was needed. For anti-keratin and -vimentin, trypsin $0.1 \%$ for 20 minutes was used. For CD45, DakoCytomation antigen retrieval solution was used for 20 minutes. Anti-CCR5 was developed either with donkey anti-goat Alexa 547 (Molecular Probes; Invitrogen Corp.) for 2-color stains or biotinylated donkey anti-goat followed by streptavidin-HRP and diaminobenzidine (DakoCytomation). For 2-color stains, slides were blocked with 2\% normal goat serum, then appropriate species-specific biotinylated antisera followed by streptavidin Alexa 488 (Molecular Probes; Invitrogen Corp.) were applied, except for the GSI-B4 lectin, in which case streptavidin-Alexa 488 was applied directly. After washing, tissue was counterstained with ToPro3 (Molecular Probes; Invitrogen Corp.), then mounted in ProLong Gold (Molecular Probes; Invitrogen Corp.). Light microscopy was examined on an Olympus Bx41 with a Canon PowerShot A60 camera. Fluorescent slides were examined on a Zeiss LSM 510 Meta confocal microscope. All slides were examined with a pinhole set to an optical thickness of $1 \mu \mathrm{m}$. 
TUNEL evaluations. End labeling of exposed 3'-OH ends of DNA fragments in paraffin-embedded tissue was undertaken with the TUNEL In Situ Cell Death Detection Kit AP (Roche Diagnostics Corp.) using the instructions provided by the manufacturer. Staining specificity was assessed by comparing the signal that was seen when terminal transferase was included and excluded from the reaction. After staining, a minimum of 20 fields of alveoli were randomly chosen, and 2,000 nuclei were counted per lung. The labeled cells were expressed as a percentage of total nuclei.

Annexin $V$ and PI evaluation. The trachea was cannulated with 20-gauge tubing, the lungs were filled with $2 \mathrm{ml}$ Dispase (Roche Diagnostic Corp.) followed by $0.5 \mathrm{ml}$ of $1 \%$ low-melting-point agarose, and the agarose was allowed to harden under crushed ice. The lungs were then placed in $2 \mathrm{ml}$ of Dispase (1 hour, room temperature) and transferred to DMEM with $25 \mathrm{mM}$ HEPES with $0.01 \%$ DNAse I (Sigma-Aldrich). After teasing apart the digested tissue, the resulting cell suspension was sequentially filtered through nylon mesh filters and collected after centrifugation (8 minutes, $130 \mathrm{~g}$ ). Annexin V and PI staining were undertaken with the annexin VFITC apoptosis detection kit (BD Biosciences) as described by the manufacturer. Analysis was undertaken by flow cytometry (BD).

Double immunobistochemistry and TUNEL evaluations. In selected experiments, TUNEL evaluations and immunohistochemistry for surfactant apoprotein-C (SP-C) were simultaneously undertaken. In these experiments, slides were deparaffinized with xylene and graded ethanol and taken to water. Microwave antigen retrieval was done with Dako $\mathrm{pH} 6$ antigen retrieval solution, and slides were treated with Dako protein block and rinsed (DakoCytomation). TUNEL (Roche Diagnostics Corp.) staining was then undertaken as described above and developed with alkaline phosphatase/ $\mathrm{BCIP} / \mathrm{NBT}$ (blue). Afterward, tissue was counterstained with goat anti-SP-C (Santa Cruz Biotechnology Inc.), anti-CD3, anti-CD31, or anti-Mac-1 (Santa Cruz Biotechnology Inc.) overnight and developed with biotinylated anti-goat/streptavidin peroxidase/AEC (red). Immunohistochemistry was undertaken as previously described by our laboratory (59).

Cigarette smoke exposure. Female C57BL/ 6 wild-type, CCR5-null, and IFN- $\gamma$ null mice were purchased from The Jackson Laboratory. Starting at 10 weeks of age, they were exposed twice a day, 5 days a week, to room air or the smoke from 2 nonfiltered standard research cigarettes (2R4; University of Kentucky) using the smoking apparatus described by Hautamaki et al. (60). After 2 months, BAL and TUNEL evaluations were undertaken as described above. After 6 months, the mice were anesthetized and sacrificed, and the trachea was cannulated. After ligation of the right main bronchus, the left lung was inflated with $0.5 \%$ low temperature-melting agarose in $10 \%$ PBS-buffered formalin at a constant pressure of $25 \mathrm{~cm}$. This allowed for homogenous expansion of lung parenchyma as described by Halbower et al. (61). The lungs were then fixed in 10\% PBS-buffered formalin for 24 hours, sectioned, and evaluated using histologic, immunohistologic, and morphologic methods as described above.

Statistics. Normally distributed data are expressed as mean \pm SEM and were assessed for significance by Student's $t$ test or ANOVA as appropriate. Data that were not normally distributed were assessed for significance using the Wilcoxon's rank-sum test for groups of 2 or the Kruskal-Wallis statistic for groups of 3 (human tissue results). Statistical analysis was performed using Stata (version 7.0; StataCorp LP) and DeltaGraph (RockWare Inc.). Statistical significance was defined at a level of $P<0.05$.

\section{Acknowledgments}

The authors thank Kathleen Bertier for excellent secretarial assistance and Suping Chen for excellent technical assistance. These studies were funded by NIH grants HL 56389, HL 064242, and HL 078744 (to J.A. Elias).

Received for publication February 25, 2005, and accepted in revised form September 13, 2005.

Address correspondence to: Jack A. Elias, Section of Pulmonary and Critical Care Medicine, Yale University School of Medicine, 300 Cedar Street (S441D TAC), PO Box 208057, New Haven, Connecticut 06520-08057, USA. Phone: (203) 785-4163; Fax: (203) 785-3826; E-mail: jack.elias@yale.edu.
1. Schroder, K., Hertzog, P.J., Ravasi, T., and Hume, D.A. 2004. Interferon-gamma: an overview of signals, mechanisms and functions. J. Leukoc. Biol. 75:163-189.

2. Tellides, G., et al. 2000. Interferon-gamma elicits arteriosclerosis in the absence of leukocytes. Nature. 403:207-211.

3. Bouma, G., and Strober, W. 2003. The immunological and genetic basis of inflammatory bowel disease. Nat. Rev. Immunol. 3:521-533.

4. Sandler, N.G., Mentink-Kane, M.M., Cheever, A.W., and Wynn, T.A. 2003. Global gene expression profiles during acute pathogen-induced pulmonary inflammation reveal divergent roles for Th1 and Th2 responses in tissue repair. J. Immunol. 171:3655-3667.

5. Lundin, K.E., et al. 2003. Oats induced villous atrophy in coeliac disease. Gut. 52:1649-1652.

6. Vervoordeldonk, M.J., and Tak, P.P. 2002. Cytokines in rheumatoid arthritis. Curr. Rheumatol. Rep. 4:208-217.

7. Garlet, G.P., Martins, W., Jr., Ferreira, B.R., Milanezi, C.M., and Silva, J.S. 2003. Patterns of chemokines and chemokine receptors expression in different forms of human periodontal disease. J. Periodontal. Res. 38:210-217.

8. Ben Ahmed, M., Houman, H., Miled, M., Dellagi, K., and Louzir, H. 2004. Involvement of chemokines and Th1 cytokines in the pathogenesis of mucocutaneous lesions of Bechet's disease. Arthritis Rheum. 50:2291-2295.

9. Borra, R.C., et al. 2004. The Th1 /Th2 immunetype response of the recurrent aphthous ulceration analyzed by cDNA microarray. J. Oral Pathol. Med. 33:140-146.

10. Katakai, T., Hara, T., Sugai, M., Gonda, H., and Shimizu, A. 2003. Th1-biased tertiary lymphoid tissue supported by CXC chemokine ligand 13-producing stromal network in chronic lesions of autoimmune gastritis. J. Immunol. 171:4359-4368.

11. Foxman, E.F., et al. 2002. Inflammatory mediators in uveitis: differential induction of cytokines and chemokines in Th1-versus Th2-mediated ocular inflammation. J. Immunol. 168:2483-2492.

12. Ehlers, S., et al. 2001. Alphabeta T cell receptor-positive cells and interferon-gamma, but not inducible nitric oxide synthase, are critical for granuloma necrosis in a mouse model of mycobacteria-induced pulmonary immunopathology. J. Exp. Med. 194:1847-1859.

13. Saetta, M., et al. 2003. Increased proportion of CD8+ T-lymphocytes in the paratracheal lymph nodes of smokers with mild COPD. Sarcoidosis Vasc. Diffuse Lung Dis. 20:28-32.

14. Saetta, M., et al. 2002. Increased expression of the chemokine receptor CXCR3 and its ligand CXCL10 in peripheral airways of smokers with chronic obstructive pulmonary disease. Am. J. Respir. Crit. Care Med. 165:1404-1409.

15. Saetta, M., et al. 1999. CD8+ve cells in the lungs of smokers with chronic obstructive pulmonary disease. Am. J. Respir. Crit. Care Med. 160:711-717.

16. O’Shaughnessy, T.C., Ansari, T.W., Barnes, N.C., and Jeffery, P.K. 1997. Inflammation in bronchial biopsies of subjects with chronic bronchitis: inverse relationship of CD8+ T lymphocytes with
FEV1. Am. J. Respir. Crit. Care Med. 155:852-857.

17. Cosio, M.G., and Guerassimov, A. 1999. Chronic obstructive pulmonary disease. Am. J. Respir. Crit. Care Med. 160:S21-S25.

18. Grumelli, S., et al. 2004. An immune basis for lung parenchymal destruction in chronic obstructive lung disease and emphysema. PLoS Med. 1:e8. doi:10.1371/journal.pmed.0010008.

19. Wang, Z., et al. 2000. Interferon gamma induction of pulmonary emphysema in the adult murine lung. J. Exp. Med. 192:1587-1600.

20. Senior, R.M., and Shapiro, S.D. 1998. Chronic obstructive pulmonary disease: epidemiology, pathophysiology, and pathogenesis. In Fishman's pulmonary diseases and disorders. A.P. Fishman et al., editors. McGraw-Hill, Inc. New York, New York, USA. 659-681.

21. Sutherland, E.R., and Cherniack, R.M. 2004. Management of chronic obstructive pulmonary disease. N. Engl. J. Med. 350:2689-2697.

22. Hogg, J.C., et al. 2004. The nature of small-airway obstruction in chronic obstructive pulmonary disease. N. Engl. J. Med. 350:2645-2653.

23. Saetta, M. 1999. Airway inflammation in chronic obstructive pulmonary disease. Am. J. Respir. Crit. Care Med. 160:517-520.

24. Majo, J., Ghezzo, H., and Cosio, M.G. 2001. Lymphocyte population and apoptosis in the lungs of smokers and their relation to emphysema. Eur. Respir. J. 17:946-953.

25. Aoshiba, K., Yokohori, N., and Nagai, A. 2003. Alveolar wall apoptosis causes lung destruction and emphysematous changes. Am. J. Respir. Cell Mol. 
Biol. 28:555-562.

26. Segura-Valdez, L., et al. 2000. Upregulation of gelatinases $\mathrm{A}$ and $\mathrm{B}$, collagenases 1 and 2, and increased parenchymal cell death in COPD. Chest. 117:684-694.

27. Kasahara, Y., et al. 2000. Inhibition of VEGF receptors causes lung cell apoptosis and emphysema. J. Clin. Invest. 106:1311-1319.

28. Kasahara, Y., et al. 2001. Endothelial cell death and decreased expression of vascular endothelial growth factor and vascular endothelial growth factor receptor 2 in emphysema. Am. J. Respir. Crit. Care Med. 163:737-744.

29. Algood, H.M., and Flynn, J.L. 2004. CCR5-deficient mice control Mycobacterium tuberculosis infection despite increased pulmonary lymphocytic infiltration. J. Immunol. 173:3287-3296.

30. van Deventer, H.W., et al. 2005. C-C chemokine receptor 5 on stromal cells promotes pulmonary metastasis. Cancer Res. 65:3374-3379.

31. Fraziano, M., et al. 1999. Expression of CCR5 is increased in human monocyte-derived macrophages and alveolar macrophages in the course of in vivo and in vitro Mycobacterium tuberculosis infection. AIDS Res. Hum. Retroviruses. 15:869-874.

32. Mack, M., et al. 2001. Expression and characterization of the chemokine receptors CCR2 and CCR5 in mice. J. Immunol. 166:4697-4704.

33. Kunkel, E.J., et al. 2002. Expression of the chemokine receptors CCR4, CCR5, and CXCR3 by human tissue-infiltrating lymphocytes. Am. J. Pathol. 160:347-355.

34. Santucci, M.B., et al. 2004. Expansion of CCR5+ CD4+ T-lymphocytes in the course of active pulmonary tuberculosis. Eur. Respir. J. 24:638-643.

35. Huffnagle, G.B., et al. 1999. Cutting edge: role of $\mathrm{C}-\mathrm{C}$ chemokine receptor 5 in organ-specific and innate immunity to Cryptococcus neoformans. J. Immunol. 163:4642-4646.

36. Aliberti, J., et al. 2000. CCR5 provides a signal for microbial induced production of IL-12 by CD8 alpha+ dendritic cells. Nat. Immunol. 1:83-87.

37. Zhou, Y., Huang, D., Farver, C., and Hoffman, G.S. 2003. Relative importance of CCR5 and antineutrophil cytoplasmic antibodies in patients with Wegener's granulomatosis. J. Rheumatol. 30:1541-1547.
38. Katchar, K., Eklund, A., and Grunewald, J. 2003. Expression of Th1 markers by lung accumulated $\mathrm{T}$ cells in pulmonary sarcoidosis. J. Intern. Med. 254:564-571.

39. Johnston, C.J., Williams, J.P., Okunieff, P., and Finkelstein, J.N. 2002. Radiation-induced pulmonary fibrosis: examination of chemokine and chemokine receptor families. Radiat. Res. 157:256-265.

40. Nissinen, R., et al. 2003. CCR3, CCR5, interleukin 4, and interferon-gamma expression on synovial and peripheral $\mathrm{T}$ cells and monocytes in patients with rheumatoid arthritis. J. Rheumatol. 30:1928-1934.

41. Luckow, B., et al. 2004. Reduced intragraft mRNA expression of matrix metalloproteinases $\mathrm{Mmp} 3$, Mmp12, Mmp13 and Adam8, and diminished transplant arteriosclerosis in CCR-5-deficient mice. Eur. J. Immunol. 34:2568-2578.

42. Algeciras-Schimnich, A., et al. 2002. CCR5 mediates Fas- and caspase- 8 dependent apoptosis of both uninfected and HIV infected primary human CD4 T cells. AIDS. 16:1467-1478.

43. Cartier, L., Dubois-Dauphin, M., Hartley, O., Irminger-Finger, I., and Krause, K.H. 2003. Chemokine-induced cell death in CCR5-expressing neuroblastoma cells. J. Neuroimmunol. 145:27-39.

44. John, A.E., and Lukacs, N.W. 2003. Chemokines and asthma. Sarcoidosis Vasc. Diffuse Lung Dis. 20:180-189.

45. Lukacs, N.W., Oliveira, S.H., and Hogaboam, C.M. 1999. Chemokines and asthma: redundancy of function or a coordinated effort? J. Clin. Invest. 104:995-999.

46. Gonzalo, J.A., et al. 1998. The coordinated action of CC chemokines in the lung orchestrates allergic inflammation and airway hyperresponsiveness. J. Exp. Med. 188:157-167.

47. Zimmermann, N., Hershey, G.K., Foster, P.S., and Rothenberg, M.E. 2003. Chemokines in asthma: cooperative interaction between chemokines and IL-13. J. Allergy Clin. Immunol. 111:227-242; quiz 243.

48. Ma, B., et al. 2004. The C10/CCL6 chemokine and CCR1 play critical roles in the pathogenesis of IL-13-induced inflammation and remodeling. J. Immunol. 172:1872-1881.

49. Di Stefano, A., et al. 2004. Cellular and molecular mechanisms in chronic obstructive pulmonary disease: an overview. Clin. Exp. Allergy. 34:1156-1167.
50. Cosio, M.G., and Majo, J. 2002. Inflammation of the airways and lung parenchyma in COPD: role of T cells. Chest. 121:160S-165S.

51. Saetta, M. 1998. Mechanisms of bronchial obstruction in COPD and emphysema: from anatomopathology to respiratory function [In French]. Rev. Mal. Respir. 15(Suppl. 2):S17-S19.

52. Song, H.K., et al. 2003. Specialized CC-chemokine secretion by Th 1 cells in destructive autoimmune myocarditis. J. Autoimmun. 21:295-303.

53. Joza, N., Kroemer, G., and Penninger, J.M. 2002. Genetic analysis of the mammalian cell death machinery. Trends Genet. 18:142-149.

54. Werner, A.B., de Vries, E., Tait, S.W., Bontjer, I., and Borst, J. 2002. Bcl-2 family member Bfl-1/A1 sequesters truncated bid to inhibit is collaboration with pro-apoptotic Bak or Bax. J. Biol. Chem. 277:22781-22788.

55. Kuziel, W.A., et al. 2003. CCR5 deficiency is not protective in the early stages of atherogenesis in apoE knockout mice. Atherosclerosis. 167:25-32.

56. He, C.H., et al. 2005. Bcl-2-related protein A1 is an endogenous and cytokine-stimulated mediator of cytoprotection in hyperoxic acute lung injury. J. Clin. Invest. 115:1039-1048. doi:10.1172/JCI200523004.

57. Zheng, T., et al. 2000. Inducible targeting of IL-13 to the adult lung causes matrix metalloproteinase- and cathepsin-dependent emphysema. J. Clin. Invest. 106:1081-1093.

58. Zhu, Z., et al. 2002. IL-13-induced chemokine responses in the lung: role of CCR2 in the pathogenesis of IL-13-induced inflammation and remodeling. J. Immunol. 168:2953-2962.

59. Lanone, S., et al. 2002. Overlapping and enzymespecific contributions of matrix metalloproteinases- 9 and -12 in IL-13-induced inflammation and remodeling. J. Clin. Invest. 110:463-474. doi:10.1172/JCI200214136

60. Hautamaki, R.D., Kobayashi, D.K., Senior, R.M., and Shapiro, S.D. 1997. Requirement for macrophage elastase for cigarette smoke-induced emphysema in mice. Science. 277:2002-2004.

61. Halbower, A.C., Mason, R.J., Abman, S.H., and Tuder, R.M. 1994. Agarose infiltration improves morphology of cryostat sections of lung. Lab. Invest. 71:149-153. 